\title{
Competence versus Trustworthiness: What Do Voters Care About?
}

\author{
Fabio Galeotti \\ University of East Anglia \\ Daniel John Zizzo* \\ University of East Anglia
}

Version: March 2014

\begin{abstract}
Appointing public officials is an important feature of modern democracies. Citizens are periodically asked to select amongst different candidates whom they want to appoint as public officials in central or local governments. There may be a trade-off on the extent to which candidates are seen as competent versus the extent to which they are seen as trustworthy. In our experiment, we ask voters to select a public official, on the competence and trustworthiness of which their final payoffs depend. We measure the competence of candidates in a real effort task and their trustworthiness in a trust game, and provide this information to voters when they make their voting decision. By looking at cases where there is a competence-trustworthiness trade-off, we can then measure the extent to which competence and trustworthiness matter in electoral decisions. We find that, in general, most voters tend to select the candidate rationally, based on who provides the highest expected profit irrespectively of trustworthiness and competence, but there is a bias towards caring about trustworthiness when the difference in expected profits between the two candidates is small enough.
\end{abstract}

Keywords: trust game, competence, trustworthiness, election.

JEL classification numbers: C72, C91, D72.

* Corresponding author. E-mail: d.zizzo@uea.ac.uk. Phone: +44-1603-593668; fax: +441603-456259; Address: CBESS and School of Economics, University of East Anglia, Norwich NR4 7TJ, UK. We wish to thank seminar participants at the CBESS (University of East Anglia) and GATE (University of Lyon), Abhijit Ramalingam, Pieter Serneels, and Theodore Turocy for useful feedback and advice, and CBESS and University of East Anglia for financial support. The usual disclaimer applies. 


\section{Introduction}

We present an experiment on the preferences of voters over candidates in public elections. We are interested in two main characteristics that define the quality of a candidate: competence and trustworthiness. ${ }^{1}$ Competence refers to the ability of a potential public official to properly perform his/her job, identifying and employing the appropriate policies that enable her to get the job done. Trustworthiness refers to the general attitude of the potential public official to fulfill the trust that the voters have placed on him or her; it usually implies a general aversion towards corrupted practices such as bribery, kickbacks, and public embezzlement which would benefit the public official to the detriment of the public.

Why may people have a preference over one of the two characteristics that define the quality of a public official? From a traditional economic point of view, a rational and purely self-interested voter should always select the candidate that ensures the highest expected return for the elector irrespectively of everything else. The underlying idea - well captured by Bill Clinton's 1992 presidential campaign strategist James Carville in his slogan "[it's] the economy, stupid" - is that people care only about the economy and want candidates who are able to improve it, and therefore their own financial position, irrespectively of everything else. The results of this study will tell us whether this is true or not based on the preferences of the voters over the characteristics of the candidates. In addition, our experiment may help us understand why democracies may at times suffer from endemic dishonesty and corruption at the public level. If voters in fact display a rational and profit-maximizing voting behavior or a preference for competence over trustworthiness, the existence of corruption and dishonesty in modern democracies might be explained by people's voting preferences.

Voters may however be reluctant to support an untrustworthy candidate if, for instance, they display what has been referred as "betrayal aversion", that is a general dislike to "being betrayed beyond the mere payoff consequences" (Bohnet et al., 2008, p. 295), or if

\footnotetext{
${ }^{1}$ In a previous study by Caselli and Morelli (2004), the authors used the term honesty instead of trustworthiness to identify one of the two main characteristics that define the quality of a public official. Clearly, the two concepts are related and the difference is usually subtle. A person is honest if she is sincere, truthful and reliable, and avoids cheating or lying. A person is trustworthy if she is reliable and willing to fulfil the trust that has been placed on her. In the context of electoral choices, when an elector votes for a candidate, he places trust on her, hoping that she will fulfil the interests of the public, usually avoiding any dishonest practices. Hence, trustworthiness is a more general term to use in order to define the quality of a public official, and, under certain conditions, it may be more relevant than honesty in driving the electoral choices of voters. For instance, an elector may vote for a candidate who is willing to adopt dishonourable measures or cheat in order to realize the interests of her constituency. In the context of our experiment, the two concepts are perfectly interchangeable as honesty implies trustworthiness and vice versa.
} 
they care more about the process by which the payoffs are generated rather than the final payoffs (see, e.g., Rabin, 1993). Similarly, voters may be sensitive to a social norm that prescribes to punish a candidate who proves to be untrustworthy. As a result, voters may vote for a candidate who is more reliable but overall less worthwhile than the contender in terms of expected payoffs.

The opposite, also plausible, possibility is that voters may support the more competent candidate, quite independently of the trustworthiness of the alternative candidates and the expected returns associated to each of them. This may be the case if, for instance, voters think that the misuse of public power for personal benefit at the public level is a fact of life and, hence, justified (Peters and Welch, 1980) or if there is so much distrust in the public system that voters believe that the election of a trustworthy public official would have no impact whatsoever on the system or only a marginal one. ${ }^{2}$

There are other possible explanations of why voters choose a certain candidate over another which abstract from the pure preferences of the voters over trustworthiness and competence. Most notably, voters can be affected by the quality and level of information on the candidates available to them at the moment of the vote (Peters and Welch, 1980). ${ }^{3}$ In this study, we do not investigate the impact of these other factors that may affect the decision making of the voters in elections, but we focus solely on the voters' preferences over trustworthiness and competence, in a context where the candidates differ only over these two characteristics and where the voters are fully informed about them.

There can be found many anecdotes, or even more formal evidence, of real-world situations which could be used to support either the primacy of trust or that of competence for voting behavior. For instance, the success of the anti-establishment movement of the comedian Beppe Grillo at the general and local elections in Italy over the 2012 and 2013 might be explained by a greater weight assigned by a significant proportion of voters to trustworthiness rather than competence. Many voters might have voted for Grillo's party because of its choice to propose ordinary voters as candidates, with no experience on politics

\footnotetext{
2 According to the 2012 corruption perception index published by the Transparency Organization (http://www.transparency.org/cpi2012), many countries do indeed present very high perceived levels of corruption in the public sector that could justify a total disinterest of the voters in the trustworthiness of the candidates.

${ }^{3}$ Other important aspects that may influence the electoral choices of the voters are, for example, the electors' partisanship to a certain ideology or party or the sensitivity of certain electors to some attractive characteristics of a candidate such as beauty or charisma.
} 
and public offices, but, as Grillo emphasized during his political campaign, much more trustworthy than conventional politicians (Bartlett, 2013). A dislike of voters for untrustworthy candidates may also explain why, in certain cases, candidates discovered or suspected to be implicated in corruption scandals fail to be elected or experience a significant drop in voters' support. For instance, in the elections of the US House of Representatives Peters and Welch (1980) and Welch and Hibbing (1997) found that incumbent candidates touched by corruption allegations lost more often their seats and received about 10 percentage points less than incumbent candidates with no corruption accusations.

A significant number of other cases seem however to support the opposite conjecture that voters are motivated by their final expected payoffs or care more about the competence of candidates rather than the trustworthiness. For instance, many of the parliamentarians who were involved in the 2009 UK parliamentary expenses scandal ${ }^{4}$ held their seats in the 2010 general elections and experienced only a marginal drop in voters' support (about $1.5 \%$ on average; Eggers and Fischer, 2011). In Brazil, the former Brazilian President Luis Inacio Lula da Silva won the 2006 general elections regardless of the corruption scandals that plagued his previous administration and after a mandate characterized by steady economic growth and decrease in poverty for Brazil (Winters and Weitz-Shapiro, 2013).

Although these examples may provide important insights on how voters vote in public elections, they cannot be used to infer the preferences of voters over trustworthiness and competence as many other factors may have played a role in voting decisions. Research is needed to uncover these preferences and isolate them from other influences. Furthermore, in modern democratic elections, the vote is secret and anonymous. As a result, real-world data on voters' preferences is typically collected only in aggregate form after an election or via public opinion polls or surveys. However, aggregate data are usually difficult to interpret due to the lack of control over many unobservable variables, in primis the individual characteristics of the voters. In addition, the answers of voters to surveys and public opinion polls are considered to be highly affected by social pressure, especially because voters are asked about sensitive topics such as political preferences, and, therefore, not fully reliable (DeMaio, 1984).

\footnotetext{
${ }^{4}$ In 2009, several members of the UK parliaments misused their permitted allowances and made inappropriate expenses claims for personal benefits.
} 
By means of a lab experiment, we are able to bypass these limitations. We can collect data on individual voting behavior which is usually difficult to analyze with standard empirical approaches. In our experiment, we ask voters to select a public official, based on the competence and trustworthiness of which their final payoffs depend. We measure the competence of the candidates in a real effort task and their trustworthiness in a trust game. We then provide this information to the voters and ask them to select the public official. By looking at cases where there is a competence-trustworthiness trade-off, we can then measure the extent to which competence and trustworthiness matter in electoral decisions, or whether in the end only the expected financial bottom line for voters matters. We find that, in general, most voters tend to select the candidate rationally, based on who provides the highest expected profit irrespectively of trustworthiness and competence. That said, there is a bias towards caring about trustworthiness when the difference in expected profits between the two candidates is small enough.

The remaining of the paper is organized as follows. Section 2 reviews the literature related to this study. Section 3 presents the experimental design. Section 4 describes the hypotheses to be tested and the theoretical background. Section 5 presents the results. Section 6 discusses the results, and Section 7 concludes.

\section{Related literature}

To the best of our knowledge, there is no study that investigates the extent to which competence and trustworthiness matter in electoral decisions. That said, one strand of related literature is about electoral delegation. In our experiment, a subject is chosen by some voters to be the public official and act for them. Several studies investigate the behavioral implications of delegating a decision about outcomes to another person (e.g. Corazzini et al., 2012; Hamman et al., 2011; Samuelson and Messick, 1986; Samuelson et al., 1984; Messick et al., 1983). These studies focus primarily on the delegate's behavior and its implications in term of welfare rather than the preferences of the people over the characteristics of the potential delegates. Similarly, voting preferences on the characteristics of the potential leaders is not a topic covered in the economic research on leadership, whereas it is the focus of our paper. ${ }^{5}$

\footnotetext{
${ }^{5}$ A public official can be in fact seen in many respects as a leader. The literature on leadership mostly focuses on the impact of leading-by-example (e.g. Gäcther et al., 2012; Güth et al., 2007; Potters et al., 2007; Moxnes and van der Hejden, 2003). Some papers compare the implications of having randomly selected leaders with
} 
Another stream of literature related to our study is about honesty in decision making. In our experiment, voters are asked to elect a public official who can appropriate part or all of a common good by underreporting its value. Economists have empirically investigated dishonesty mostly using experimental data. Some have studied lying and dishonesty in cheap talk games where some players can send true or false message regarding some kind of private information (e.g. future moves) to other players (e.g. Sutter, 2009; Gneezy, 2005; Croson, 2005). In these studies, deception is totally disclosed to the experimenter. Other scholars not only in economics - have studied unobserved lying behavior by tracing its distribution from subjects' reported results of a dice roll, coin flip or matrix task (e.g. Fischbacher and Heusi, 2013; Hao and Houser, 2013; Abeler et al., 2012; Houser et al., 2012; Bucciol and Piovesan, 2011; Mazar and Ariely, 2006).

Our study is also related to some works on corruption. Barr at al. (2009) and Azfar and Nelson (2007) used a Public Servant's Game to study corruption in service delivery. In this game, one subject is assigned the role of service provider (or executive), a second subject the role of monitor (or attorney general), and the remaining subjects (6 subjects) are community members. The decision of the service provider, that is how many tiles (from a random distribution) to allocate to the community, is similar to the one of the public official in our experiment. A few economists and political scientists have also examined the extent to which voters may support corrupted incumbents in public elections (e.g. Peters and Welch, 1980; Welch and Hibbing, 1997; Ferraz and Finan, 2008; Winters and Weitz-Shapiro, 2013; Bågenholm, 2013). These studies are to some extent linked to ours since corruption may be a sign of untrustworthiness, particularly if the interests of the voters are aligned with those of the public. These works primarily used aggregate-level empirical approaches and focus solely on the impact of corruption on incumbents' re-election without investigating the trade-off between trustworthiness and competence. ${ }^{6}$

There is political science research studying the importance of the quality of the candidates, defined as a combination of integrity and competence, in electoral choices

elected leaders (e.g. Levy et al., 2011; Brandts et al., 2012; Kocher et al., 2013), leaders appointed based on their past contribution (e.g. Gäcther and Renner, 2005), leaders appointed based on participant's performance in a pre-task (e.g. Kumru and Vesterlund, 2010), and self-selected leaders (e.g. Rivas and Sutter, 2011; Arbak and Villeval, 2011). In our experiment, the "leader" is endogenously selected, as in some of this research. However, in contrast to this literature, our study is not about leadership-by-example, and we are not interested on the leader and followers' behavior but on subjects' preferences over the characteristics of the potential leaders.

${ }^{6}$ An exception is the political study of Winters and Weitz-Shapiro (2013) who employed a non-incentivized survey experiment to investigate the attitude of respondents towards hypothetical incumbent politicians (vignettes) described in the form of qualitative sentences. 
(Mondak and Huckfeldt, 2006; Mondak, 1995; Kulisheck and Mondak, 1996; McCurley and Mondak, 1995). Mondak (1995) investigated the permanence of incumbents in the US House of Representatives in relation to the quality of the incumbents, measured as an index of competence and integrity constructed with content analysis. He found that high-quality US House members remained in office longer than low-quality members. McCurley and Mondak (1995) combined the aggregate-level data on the quality of US House of Representatives' incumbents with individual-level post-election survey data to explore whether the skill and integrity of the candidates affect the voters' evaluation of the candidates and their voting choice. They found that the quality scores do affect the evaluation of the candidates. Similar findings are provided by Kulisheck and Mondak (1996) who investigated whether the information concerning the quality of hypothetical candidates influences the voting choice of subjects in a survey experiment. Mondak and Huckfeldt (2006) collected data from a series of survey experiments and a national survey to study the accessibility of the competence and integrity of hypothetical candidates in the evaluation of the contenders, and how people respond to these characteristics relative to partisanship and ideology. They found that competence and integrity are slightly more accessible than partisanship and ideology, and are perceived favorably by subjects. Altogether these studies provide evidence that the quality of candidates matter in national elections. However, they are inconclusive on which dimension of the quality matters the most. In addition, they present several features in relation to which our laboratory experiment approach based on an incentivized environment is able to provide a significant contribution. ${ }^{7}$

\section{Experimental Design}

\section{A. $\quad$ Outline}

\footnotetext{
${ }^{7}$ First, when aggregate-level empirical approaches are used (e.g. Mondak, 1995; McCurley and Mondak, 1995), it is usually difficult to isolate and control for the effects of important unobservable variables, such as, for instance, the information available upon the candidates. In addition, one can question the subjectivity and precision of the measure used to identify the quality of a candidate, and the reliability of post-election surveys to measure the voters' support for a candidate (see, e.g., DeMaio, 1984; Lodge et al., 1990). Finally, when survey experiments are used (Kulisheck and Mondak, 1996; Mondak and Huckfeldt, 2006), the situations described to the subjects are hypothetical, there are no economic incentives associated with the choices, the focus is more on attitude and perception rather than behavior, and the quality of the candidates is identified only with qualitative statements and phrases. While these comments are not to deny the value of these studies, they suggest that an experimental approach of the kind we use would be especially useful to complement them.
} 
The experiment was conducted at the University of East Anglia between March and June 2013. 240 subjects participated in 20 experimental sessions (12 subjects per session). ${ }^{8}$ The experiment was fully computerized and programmed with the z-Tree software (Fischbacher, 2007). Each session consisted of three stages (the Real Effort Task, the Trust Game, and the Official's Dilemma Game) and a final questionnaire. ${ }^{9}$ At the beginning of each stage, subjects received both computerized and printed instructions. ${ }^{10}$ These were context-free and written avoiding any suggestive terminology. Each set of instructions was followed by a control questionnaire which purpose was to check subjects' understanding of the instructions. Clarifications were given aloud for public knowledge. During the experiment, payoffs were calculated in points and converted to British pounds at the end of the experiment ( 1 point $=$ 20 pence). Each subject earned on average $£ 12.47$ (around 19-20 US dollars) including $£ 2$ of show-up fee. Subjects were paid in private and in cash in a separate room outside the lab by a research assistant who was not present during the experiment and who was not aware of its content. Each session lasted around 1 hour and 15 minutes. We ran 2 treatments, described below: the Baseline treatment (14 sessions), and the CIL (Conditional Information Lottery) treatment (6 sessions). For each treatment, in half of the sessions we had the real effort task and the trust game second, and in the other half the reverse. Upon arrival to the lab, each subject was registered for the experiment and randomly assigned to a computer desk which was separated from the others by partitions. Afterwards, subjects received the instructions for the first stage.

\section{B. $\quad$ The Baseline treatment}

The Real effort Task Stage. The task for this stage was performed individually by each subject and consisted in counting the number of $1 \mathrm{~s}$ in a series of tables containing $0 \mathrm{~s}$ and $1 \mathrm{~s}$ for 10 minutes (see, e.g., Abeler et al., 2009; Pokorny, 2008). ${ }^{11}$ Each subject earned 1 point for each table that he or she correctly solved on top of the first 40 tables. This number was

\footnotetext{
${ }^{8}$ Subjects were randomly recruited with the on-line software ORSEE (Greiner, 2004). Subjects were mostly students with different socio-demographic background (details are provided in the online appendix). No subject participated in more than one session.

${ }^{9}$ At the beginning of the experiment, subjects were informed that there were many stages in the experiment, but the details of each stage were revealed to subjects only at the beginning of each stage. This is because we want to minimize strategic behavior. We also made clear in the instructions that the information provided by the subjects in each stage may be reported to other participants at later stage of the experiment but anonymity will be preserved.

${ }^{10}$ Instructions are available in the online appendix.

${ }^{11}$ A table consisted of a $5 \times 5$ matrix of $0 \mathrm{~s}$ and $1 \mathrm{~s}$. For each table, the computer randomly generated a number of $0 \mathrm{~s}$ and $1 \mathrm{~s}$ in a random order. In a given session, all the subjects faced the same series of randomly generated tables.
} 
calibrated based on the results of pilot sessions in order to obtain a similar degree of dispersion between our measure of competence and our measure of trustworthiness, and to ensure that everyone was able to pass the threshold of $40 .{ }^{12}$ In particular, we wanted to avoid that the voting decisions of the subjects were biased towards one characteristic or the other because of the different (normalized) degree of variation of the two characteristics. We chose this particular task because it provides enough variation in performance. The task is also simple and does not require any particular knowledge. At the same time, it is tedious and, therefore, mentally costly for the subjects. Finally, the experimenter does not benefit from the output of the task. ${ }^{13}$

In this stage of the experiment, we obtained, for each subject, a measure of competence calculated as the number of tables correctly solved on top of the first 40 tables correctly solved.

The Trust Game Stage. The other stage 1 or 2 of the experiment, depending on the session sequence, was a modified version of the standard one-shot trust game proposed by Berg et al. (1995). In particular, each subject was randomly matched with another participant. For each pair of subjects, one participant was randomly assigned the role of truster, while the other the role of trustee. The truster received an endowment of 30 points and decided whether to transfer or not the entire endowment to the trustee (it was a binary choice: transfer all/do not transfer at all). If the truster decided to transfer the 30 points to the trustee, these were multiplied by 3 and the trustee received 90 points. The trustee could then decide to give back any amount to the truster between a minimum of 9 points and a maximum of 90 points. Since the roles were revealed only at the end of the experiment, each subject made a decision in both roles ${ }^{14}$ using a strategy method. In particular, each subject first decided how many points he or she wished to return to the truster if he or she were to be assigned the role of trustee and the truster were to transfer the 30 points to the trustee. Then, each subject decided whether he or she wanted to transfer the 30 points or not to the trustee if he or she were assigned the role of truster. This mechanism allowed us to collect a measure of trustworthiness for each participant. In particular, the proportion of points sent back to the truster by each subject in the role of trustee was our measure of trustworthiness. Note that, in order to minimize

\footnotetext{
${ }^{12}$ Only 2 subjects out of 240 did not solve more than 40 tables in the first stage of the experiment. In particular, one subject solved 36 tables and the other one 40 tables.

${ }^{13}$ These are all important features of our task since we wanted to minimize the reciprocity of subjects towards the experimenter, and to ensure that our measure of competence was minimally affected by other external influences (Abeler et al., 2009).

${ }^{14}$ Only one of the two decisions counted for the earnings depending on the role assigned.
} 
reciprocity in the following stage, the subjects could not rematch with the same person later in the experiment. In addition, we imposed a minimum amount of 9 points to be returned by the trustee in order to avoid observations at zero. This is an important aspect for the following stage as people may avoid voting for a candidate simply because he or she displays a zero in one of the characteristics rather than a minimum positive value. ${ }^{15}$ Finally, we asked people to make a decision first in the role of trustee and, then, in the role of truster. ${ }^{16}$

The Official's Dilemma Game. In stage 3 of the experiment, each participant was matched with two others to form a group of three subjects. ${ }^{17}$ The computer assigned a common fund to each triad with an initial value of 0 points. The task in this stage of the experiment was to count $1 \mathrm{~s}$ in a series of tables as in the first stage of the experiment. However, only the work of one of the three subjects counted for the earnings of this stage. This person was the public official. ${ }^{18}$ In particular, for each table that the public official solved on top of the first 40 tables correctly solved, the value of the common fund increased by 4 points. At the end of the real effort task, ${ }^{19}$ the common fund accumulated a certain value. Only the public official was informed of this value. He or she was then asked to report the value of the common fund to the other members of the triad, knowing that he or she could report any number between 0 and the true value of the common fund. The reported value of the common fund was divided equally between the three participants. The public official kept the unreported value of common fund for himself or herself. All of these rules for generating and distributing experimental earnings were common knowledge for all subjects at the point of selecting the public official: therefore, in selecting the public official, subjects knew that their earnings depended on the competence (in solving tables) and the trustworthiness (in reporting the value of the common fund) of the public official.

How was the public official selected? At the beginning of the game, each subject was informed of (a) the number of tables correctly solved by each other member of the triad in the earlier real effort task stage of the experiment; this provided a measure of the competence of

\footnotetext{
${ }^{15}$ The underlying mechanism may be similar to the one that characterized the so-called 'zero-price effect' (see, e.g., Shampanier et al., 2007). This effect has been studied in the marketing research. In this literature, the zero is associated with a cost and induces people to choose more often the option with the zero (other things being equal). In our context, the zero would be associated with a benefit and may induce people to choose less often the option with the zero (other things being equal), resulting in potential biased observations.

${ }^{16}$ This is because we wanted to minimize the possibility that the decision in the role of truster affected the decision in the role of trustee, as the latter provides our measure of trustworthiness, whereas we are not interested in the truster's decision as such in this experiment.

${ }^{17}$ In the instructions, we refrained from using any terminology (e.g. group) which could induce group identity.

${ }^{18}$ In the instructions, we used the neutral term appointed co-participant to identify the public official.

${ }^{19}$ Note that everyone could work on the task if they wanted to, and this was known at the time of voting. However, the task was incentive compatible only for the public official.
} 
each candidate; and (b) the proportion of points that each other member of the triad in the role of trustee returned to the truster in the earlier trust game stage of the experiment; this provided a measure of the trustworthiness of each candidate. Based on this information, each subject was asked to vote: that is, to choose which of the two other participants he or she wanted to appoint as the public official. Then, the computer implemented the voting decision of one randomly selected subject within each triad; this mechanism ensured that voting was incentive compatible, by removing any scope for strategic voting behavior.

Final questionnaire. After stage 3, subjects had to complete a 5-parts questionnaire, reproduced in the online appendix. The first two parts were incentivized. Part 1 was a belief elicitation questionnaire. ${ }^{20}$ In part 2, we measured the risk attitude of subjects. We employed the Eckel et al. (2012)'s task in the domain of gains. In this task, subjects had to choose one gamble out of six possible gambles. Each gamble was represented with a circle and involved two payoffs with $50 \%$ probability of occurrence each. Moving from gamble 1 to gamble 6 , both expected return and risk increased. Part 3 was the Stöber (2001)'s 17-item Social Desirability Scale (SDS17 score) which measures how much a person desires to be perceived in a positive light. Part 4 was the Christie and Geis (1970)'s 20-item Machiavellianism scale (MACH score) which measures a person's tendency to be amoral and opportunist. In the last part of the questionnaire, we collected some demographics and elicited subjects' belief about the objective of the experiment.

Payments. At the end of the experiment, the computer randomly drew a stage. Subjects were paid the earnings of that stage plus the show-up fee of 2 pounds and any additional earnings that they obtained by answering the final questionnaire.

\section{The CIL treatment}

The main purpose of the CIL treatment was to collect more data, in general and by individual, on the voting behavior of the subjects, without deceiving them. In addition, the data collected in this treatment allowed us to classify the subjects based on their voting decisions. The CIL treatment differs from the Baseline treatment only in third stage of the experiment, that is in the Official's Dilemma Game. In particular, in the CIL treatment, we employed the so-called Conditional Information Lottery (Bardsley, 2000). This technique consists in camouflaging one true task amongst other fictional tasks, with the subjects fully aware that there is a camouflage but uninformed ex-ante of which task is the true one

\footnotetext{
${ }^{20}$ The details are in the online appendix.
} 
(Bardsley, 2000). More specifically, in the selection of the public official, each subject was presented with 7 randomly ordered situations: one real and six fictional. In the real situation, each subject was informed about the actual competence and trustworthiness of the other participants within his or her group. In the fictional situations, each subject was instead presented with fictitious information about the competence and trustworthiness of the other two participants. In particular, to make the camouflage credible and realistic, the information used in the fictional situations came from situations occurred in past sessions of this experiment (the first six Baseline sessions) and chosen at random by the computer (subjects were fully informed of this). More specifically, to generate the fictional situations, the computer randomly picked situations from past sessions using a stratification procedure which followed approximately the distribution of the cases observed until then. Two fictional situations were randomly selected from the past situations where one candidate strictly or weakly dominated the other candidate in both characteristics (competence and trustworthiness). All the other four fictional situations corresponded to cases where the characteristics of the two candidates were orthogonal and differed in the extent to which the two candidates were different in terms of expected payoffs generated for the voter. In particular, one situation was randomly selected from cases where the difference in expected payoffs between the two candidates lay in the interval $[0,5]$ experimental points; a second situation from cases where the difference lay in the interval $(5,10]$ experimental points; a third situation from cases where the difference lay in the interval $(10,20]$ experimental points; and a fourth situation from cases where the difference lay in the interval $(20,50]$ experimental points. This stratified randomization allowed us to provide to the subjects enough decoys to prevent them from spotting the true situation, and, at the same time, to collect more information on the electoral choices of subjects for different level of expected payoffs of the candidates. The order of the seven situations was randomized. For each situation, each subject was asked to choose which of the two participants he or she wanted to appoint as the public official, knowing that only the decision of one participant selected at random in the real situation was implemented if the stage was chosen for payment. All the other aspects of the experiment were identical to the Baseline treatment.

As Bardsley (2000) pointed out, the CIL procedure might induce "cold" decisions because of the hypothetical nature of the task. This might actually be desirable in our experiment as voters do usually make their electoral choices in a "cold" state, since they are typically asked to vote in polling places, anytime over a span of one or two days and after the political campaign of the candidates. The CIL procedure may also dilute the incentives of the 
experiment, and increase the misunderstanding of the experimental procedures. To minimize these drawbacks, we limited the fictional situations to only 6 and made sure that subjects fully understood the instructions. ${ }^{21}$ It was also important that subjects did not spot the true situation. As we have already mentioned earlier, we adopted a procedure of stratified randomization to select the fictional situations from real situations occurred in past sessions of the experiment, making very difficult, if not impossible, for the subjects to identify the true situation. Most significantly, we can use the Baseline treatment as a control to check whether any biases were produced from using the CIL procedure.

\section{Theoretical background and hypotheses}

In this section, we set the theoretical background and present the hypotheses to be tested. Let us call $\pi_{n, j}$ the expected earnings of the generic voter $n$ if the candidate $j$ is appointed in stage 3 . This can be defined as:

$$
\pi_{n, j}=A T_{n j} C_{n j}
$$

where $A$ is the constant multiplier of voter $n$ 's profit function (equal to $4 / 3$ in our experiment, where 3 is the group size, and 4 is the value of one table correctly solved by the candidate on top of the first 40 correct tables and reported to the voter); $T_{n j}$ captures the trustworthiness of the candidate and is measured as the proportion of points returned by the candidate in the trust game stage; $C_{n j}$ captures the competence of the candidate and is measured as the number of tables correctly solved on top of the first 40 tables correctly solved in the real effort task stage. The profit function is a Cobb-Douglas with profit elasticities of competence and trustworthiness equal to 1. Each elasticity measures the responsiveness of the profit to a change in competence or trustworthiness, ceteris paribus. In particular, a $1 \%$ increase in competence would lead to a $1 \%$ increase in profit. Similarly, a $1 \%$ increase in trustworthiness would lead to a $1 \%$ increase in profit.

The voter $n$ must choose among two candidates $(\mathrm{J}=2)$. The voter obtains a certain utility if a certain candidate is elected. In particular, the utility that voter $n$ gets if candidate $j$ is appointed is $U_{n, j}, j=1,2$. Each candidate possesses two attributes (competence and trustworthiness) which are known by the voter. If the voter is rational and profit maximizing,

\footnotetext{
${ }^{21}$ As we have already mentioned early, subjects filled in a control questionnaire, followed by clarifications, to check their understanding of the instructions, with key questions regarding, for instance, the meaning of the fictional situations.
} 
she should choose the candidate that gives the highest utility, and her utility should be an increasing function of the expected earnings. For simplicity, let the utility be a standard Cobb-Douglas function ${ }^{22}$ which can be defined as follows:

$$
U_{n, j}=A T_{n j}^{\alpha_{1}} C_{n j}^{\alpha_{2}} e^{\epsilon_{n, j}}
$$

where $\alpha_{1}$ and $\alpha_{2}$ are the weights (elasticities) of the trustworthiness and the competence respectively of the candidate $j$ in the utility function of voter $n . A T_{n j}{ }^{\alpha_{1}} C_{n j}{ }^{\alpha_{2}}$ is the known component of the utility function, whereas $e^{\epsilon_{n, j}}$ is the stochastic component (unknown component). ${ }^{23}$

If the two attributes have the same weight in the utility $\left(\alpha_{1}=\alpha_{2}=\alpha\right)$, the voter cares only about his or her profit. We can rewrite the utility as a function of the profit:

$$
U_{n, j}=\pi_{n, j}^{\alpha} e^{\epsilon_{n, j}}
$$

Hypothesis 1. If voters are rational and profit maximizing, $\alpha_{1}=\alpha_{2}=\alpha$, with $\alpha>0$.

If $\alpha$ is equal to 0 , the utility does not depend on the profit. If $\alpha$ is less than 0 , it negatively depends on the profit. If $\alpha_{1}>\alpha_{2}\left(\alpha_{2}>\alpha_{1}\right)$, it means that the voter weight more the trustworthiness (competence) of the candidate over the competence (trustworthiness), and over what would be predicted by profit maximization.

Hypothesis 2. If trustworthiness matters more than competence, $\alpha_{1}$ will be greater than $\alpha_{2}$.

Hypothesis 3. If competence matters more than trustworthiness, $\alpha_{2}$ will be greater than $\alpha_{1}$.

To test the Hypotheses 1, 2 and 3, we can take the natural logarithm of the utility to obtain a linear function in parameters:

\footnotetext{
${ }^{22}$ The Cobb-Douglas function has been widely used in economics to identify the production function of a firm or the utility function of an economic agent (see, e.g., Mas-Colell et al., 1995). In our context, it is particularly useful as it allows us to estimate the weights that a voter places on the trustworthiness and competence of the candidates in a directly comparable way. In particular, the weights are expressed in terms of elasticities, that is how much the utility varies (in percentage) if trustworthiness or competence increases by $1 \%$. In addition, it is logically consistent with the essential elements of our experiment. In particular, it is directly linked to the profit function used in our experiment. More precisely, it can be reduced to a function of the profit if the weights of trustworthiness and competence are identical.

${ }^{23}$ For simplicity, we assume that the stochastic component is non-additive.
} 


$$
\ln \left(U_{n, j}\right)=V_{n, j}=\ln (A)+\alpha_{1} T_{n j}+\alpha_{2} C_{n j}+\epsilon_{n, j}
$$

Knowing that the probability that voter $n$ chooses candidate $i$ over $j$ is:

$$
P_{n, i}=\operatorname{Prob}\left(V_{n, i}>V_{n, j}\right)=\operatorname{Prob}\left(V_{n, i}-V_{n, j}>0\right)
$$

We can derive the logit choice probability assuming that the error term $\left(\epsilon_{n, j}\right)$ is iid with a Type-I extreme value distribution. The equation for the logit choice probability is:

$$
P_{n, i}=\operatorname{Prob}\left(V_{n, i}>V_{n, j}\right)=\frac{\exp \left(\alpha_{1} \ln \left(T_{n j}\right)+\alpha_{2} \ln \left(C_{n j}\right)\right)}{\sum_{j=1}^{2} \exp \left(\alpha_{1} \ln \left(T_{n j}\right)+\alpha_{2} \ln \left(C_{n j}\right)\right)}
$$

The estimation of $\alpha_{1}$ and $\alpha_{2}$ is relatively straightforward through maximum likelihood estimation as we observe the choices of the voters and we have measures of the trustworthiness and competence of the candidates.

\section{Experimental results}

\section{A. Descriptives}

Table 1 shows the average measures of competence and trustworthiness for each treatment, from the first two stages of the experiemnt. ${ }^{24}$ In the table, competence is the number of tables correctly solved on top of the first 40 tables correctly solved in the real effort task; trustworthiness is measured by the return rate, that is the proportion of points returned to the truster in the trust game. Since the Baseline and CIL treatments were equivalent in the first two stages of the experiment (i.e. the treatment manipulation involved only stage 3), we can pool their data together. There are only weakly significant differences in competence between the sessions where the real effort task stage took place first and the sessions where the trust game stage was played first (Mann-Whitney test, $p=0.094) .{ }^{25} \mathrm{We}$ do not detect any statistically significant differences in the return rate between having first played the real effort Task and the trust game $(p=0.419) .{ }^{26}$ The coefficient of variation for

\footnotetext{
${ }^{24}$ The focus of this paper is on the voting choice and the information that subjects had to make this choice. As a result, we do not focus on the public official's behavior in the official dilemma game, once selected. The online appendix contains an analysis of the public official's choices in the official dilemma game, as well as more analysis of stages 1 and 2 .

${ }^{25}$ A possible interpretation of why subjects performed slightly better in the sessions where the real effort task was played first than in the sessions where the trust game was played first is that they were cognitively less tired when the real effort task was played in the first stage rather than in the second stage. All $p$ values reported in this paper are two-sided.

${ }^{26} \mathrm{We}$ also ran an OLS regression (for competence) and Tobit regression (for trustworthiness) where we control for the socio-demographic and psychological characteristics of the subjects (see the online appendix).
} 
competence, measured as the standard deviation over the mean, is 0.466 . The coefficient of variation for trustworthiness is 0.518 . The normalized measure of dispersion, captured by the coefficient of variation, is similar between competence and trustworthiness. This means that the voting decision of the subjects may not be affected by a different degree of dispersion between the two variables. Also, both the competence measured in the real effort task stage and the trustworthiness measured in the trust game stage were positively correlated with the public officials' competence and trustworthiness respectively in stage 3 (Spearman's $\rho=0.89$ and 0.28 , and $p<0.001$ and $=0.011$, respectively). ${ }^{27}$ This indicates that both measures were valid proxies of the public officials' behavior in stage 3 .

\section{[Table 1 about here]}

To analyze the electoral choices of subjects, we first consider the number of times subjects voted for a candidate for each possible electoral situations that occurred in the experiment (Table 2). If we look at the interesting situations where there was a trade-off between trustworthiness and competence, subjects seemed to vote more often for the trustworthy candidate as opposed to the more competent one. We can test more formally whether the proportion of situations where subjects chose the more trustworthy candidate significantly differs from $50 \%$. The result of a binomial test indicates that the proportion of situations where people voted for the more trustworthy subject (about 59\%) is significantly different from $50 \%(p<0.001) .{ }^{28}$ It is however possible that subjects voted more often for the more trustworthy candidate simply because the latter was more often associated to higher expected payoffs. In other words, people did not vote for the more trustworthy candidate because of his/her trustworthiness, but because the combination of his/her levels of competence and trustworthiness entailed higher expected payoffs compared to the other candidate. This means that we will need to take into account the expected payoffs of the two candidates if we want to correctly study the electoral preferences of the voters.

\section{[Table 2 about here]}

\footnotetext{
${ }^{27}$ In stage 3, competence is measured as the number of tables correctly solved on top of the first 40 tables correctly solved, while trustworthiness is measured as the proportion of tables reported.

${ }^{28}$ In the overall sample, $p<0.001$. However, in CIL sessions, since we have multiple observations for each subject, there may be correlation between the observations and so the test may not be valid. That said, if we restrict the test to only the observations that are totally independent (Baseline sessions), we obtain exactly the same result, that is the proportion of situations where people voted for the more trustworthiness subject (about $61 \%$ in the baseline sessions) is significantly different from $50 \%(p=0.024)$.
} 
If we look at the other situations where there is no trade-off between trustworthiness and competence, in a very small proportion of cases $(5.56 \%),{ }^{29}$ subjects displayed what we refer as an inconsistent voting behavior, that is they voted for the candidate who was strictly or weakly dominated in both characteristics (trustworthiness and competence) by the other candidate. The behavior of these subjects (from now on, we will label them as inconsistent subjects) is difficult to characterize and interpret. It is likely that they made random choices during the experiment or did not take the experiment seriously. Hence, we will control for their behavior in the remaining of the analysis.

We can also look at how the probability that a candidate $i$ is elected evolves as a function of the difference in competence and trustworthiness between candidate $i$ and her rival, candidate $j$ (Figure 1). To make competence and trustworthiness graphically comparable, we standardized them, that is we subtract the mean from each value and divide the result by the standard deviation. The graph suggests first that subjects seemed to behave quite rationally as the probability of being elected was close to 1 when the candidate was superior in both characteristics compared to the contender (upper corner of the graph), and was close to 0 when the candidate was inferior in both characteristics (bottom corner of the graph). Second, the subjects seemed to slightly prefer more a trustworthy candidate to a competent one since the probability of being elected increases more steeply when the difference in trustworthiness between two candidates increases than when the difference in competence increases. We will investigate this in more detail in the regression analysis.

\section{[Figure 1 about here]}

We now consider the expected payoffs that each candidate provided to the voters. We begin by assuming that subjects had adaptive expectations, that is they took the measures of trustworthiness and competence from the earlier stages to estimate what expected payoffs would be had by each candidate if elected public official. We shall relax this assumption later. First, we look at the probability of electing the more trustworthy candidate as a function of the difference in expected payoffs $\Delta \pi$ between the more and less trustworthy candidate (Figure 2), restricting the analysis to the observations where there was a trade-off between trustworthiness and competence. The probability is obtained by computing the weighted running means of a dichotomous variable taking value 1 when the trustworthy candidate is

\footnotetext{
${ }^{29}$ More precisely, 14 subjects ( 5 in the baseline, 9 in CIL) out of 240 displayed this behavior $(5.83 \%$ of subjects).
} 
elected and 0 otherwise. For $\Delta \pi<0$ (i.e. the more trustworthy candidate is also the less profitable), profit-maximizing subjects should vote for the less trustworthy candidate as he or she is associated with higher expected payoffs. Hence, the area below the smoothed means measures the extent to which subjects voted for the more trustworthy candidate when this was not the more profitable candidate. For $\Delta \pi>0$ (i.e., the more trustworthy candidate is also the more profitable), profit-maximizing subjects should vote for the more trustworthy candidate as he or she is associated with higher expected payoffs. Hence, the area above the smoothed means measures the extent to which subjects voted for the more competent candidate when this was not the more profitable candidate. Note that the theoretical predicted probability under rational self-interest would follow a step function where the voter never chooses the more trustworthy candidate in the region where $\Delta \pi<0$, and always chooses him or her when $\Delta \pi>0$.

[Figure 2 about here]

As Figure 2 shows, choices follow fairly closely the rational self-interested prediction, in preliminary support of Hypothesis 1 . That said, the area below the weighted running means for $\Delta \pi<0$ is bigger than the area above the weighted running means for $\Delta \pi>0$. This is particularly remarkable for small differences in expected payoffs $(|\Delta \pi| \leq 5)$. This preliminary evidence suggests some preliminary support for a qualified version of Hypothesis 2: subjects seemed more likely to vote for the less profitable candidate when this was the more trustworthy one, particularly when the two candidates did not differ too much in terms of their contribution to the expected payoffs of the voter.

To look at this further, we consider how often subjects voted for the more trustworthy candidate when the latter was the less profitable one, and how often subjects voted for the more competent candidate when the latter was the less profitable one. Figure 3 reports the proportion of cases where the voters selected the less profitable candidate for each interval of absolute deviation in expected payoffs between the two candidates. ${ }^{30}$ This proportion identifies the rate of counterintuitive voting behavior and measures the proportion of cases where subjects are willing to sacrifice their expected monetary payoffs in order to select the more trustworthy or competent candidate. In aggregate but particularly when the difference in expected payoffs between the two candidates was small (between 0 and 5 experimental

\footnotetext{
${ }^{30}$ These were the same intervals that were used in the design phase of the experiment to generate the fictitious situations for the CIL treatment.
} 
points), the proportion of cases where subjects voted for the unprofitable and more trustworthy candidate was signficaintly larger than the proportion of cases where subjects voted for the unprofitable and more competenent candidate. ${ }^{31}$

[Figure 3 about here]

This is preliminary evidence of the fact that voters weighed trustworthiness more than competence, particularly when the candidates contributed a similar amount to the expected payoffs of the voters. In terms of the theoretical hypotheses presented earlier, this suggests that $\alpha_{1}$ is greater than $\alpha_{2}$, especially when the difference in expected payoffs between the two candidates is small enough.

\section{B. Regression analysis}

We now make our analysis more rigorous using regression analysis. We identify the candidate chosen by each voter with a dummy variable 'Vote' (= 1 if the candidate is chosen, 0 otherwise). For each situation faced by a generic voter $i$, we have two observations and for only one of the two the variable 'Vote' is equal to 1. Based on the theoretical background presented in a previous section, we estimate the probability that a subject votes for a certain candidate based on the characteristics of the alternative candidates. In particular, we estimate an alternative-specific conditional choice model. Since in the CIL sessions we have multiple observations per individual, we employ robust standard errors clustered at individual level. The dependent variable is the dummy 'Vote'. In Regression 1, the independent variables include the $\operatorname{logs}$ of measured trustworthiness and competence of the candidate, $\log$ (trustworthiness) and $\log$ (competence) ${ }^{32}$ In Regression 2, we also add interaction terms of these variables with a dummy variable $|\pi|>5$, which takes value 1 when the absolute deviation in expected payoffs between the two candidates is larger than 5 experimental points. In Regression 3, we also control for the demographic, psychological and behavioral

\footnotetext{
${ }^{31}$ If we restrict ourselves only the observations that are totally independent (Baseline sessions), we obtain $\chi^{2}$ test, $p=0.070$ in aggregate and 0.003 for the $[0,5)$ interval. If we exclude the inconsistent subjects, we obtain $\chi^{2}$ test, $p=0.012$ in aggregate and 0.023 for the $[0,5)$ interval. The results are if anything slightly stronger if we include the CIL treatment observations, though the validity of the tests are then questionable because of lack of independence among different observations by the same subject in the CIL treatment.

${ }^{32}$ We cannot compute the log of the competence in 12 electoral situations - where one candidate (real or fictional) did not solve more than 40 tables - out of the 401 situations characterized by a trade-off between trustworthiness and competence. This is equivalent to only the $2.99 \%$ of the relevant electoral situations. The value of competence (tables correctly solved above 40 correct tables) for these few situations is in fact zero. We thus drop these few observations from the regression analysis. Note that these 12 electoral situations come from two subjects that did not solve more than 40 tables in the Baseline sessions and that were also randomly selected as fictional candidates by the computer in few other situations of the CIL sessions.
} 
characteristics of the voters and treatment effects by interacting them with $\log$ (trustworthiness) and $\log$ (competence).$^{33}$ In particular, we control for the nationality of the subjects (UK and China), their gender, their age, whether they study economics or not, and whether they are undergraduate students or not. In addition, we control for the risk attitude of the subjects, and their scores in the SDS17 and MACH questionnaires. We also control for the sessions where the order of the real effort task and the trust game was counterbalanced, and the CIL sessions. Finally, we control for the behavior of the voters in the real effort task stage and the trust game stage by interacting the log of competence and trustworthiness of each voter with the $\log$ of the trustworthiness and competence respectively of the candidates. ${ }^{34}$ In Regressions 4-6, we control for the behavior of the inconsistent subjects by including an interaction of whether a subject was categorized as inconsistent with $\log$ (trustworthiness) and $\log$ (competence) respectively. Table 3 displays the results of the regressions.

\section{[Table 3 about here]}

In Regressions 1 and 4, both the coefficients of the log of trustworthiness $\left(\alpha_{1}\right)$ and the $\log$ of competence $\left(\alpha_{2}\right)$ are positive and significant. The coefficient of $\log$ (trustworthiness) is slightly larger than the coefficient of $\log$ (competence) but the difference is not statiscally significant ( $\chi^{2}$ test, $p=0.975$ in Regression 1 , and 0.532 in Regression 4). In Regression 4, both the interaction terms of $\log$ (trustworthiness) and $\log$ (competence) with Inconsistency are negative and statistically significant. Also, the size of the coefficients is such as to largely offset the coefficients for $\log$ (trustworthiness) and $\log$ (competence) for inconsistent subjects. We can present the first and second result.

Result 1. In line with Hypothesis 1 but in contrast to both Hypotheses 2 and 3, subjects generally displayed a rational and profit-maximizing behavior by voting for the candidate who provided the highest expected profits, irrespectvely of his or her trustworthiness and competence.

Result 2. Inconsistent subjects tended to rely less on measured competence and trustworthiness.

\footnotetext{
${ }^{33}$ Note that since our model is alternative-specific, the characteristics of the voters do not vary over the choices of the voters, and, therefore, they would be dropped out from the model. The only way to get around this problem and account for the individual characteristics of the voter is to add interaction terms between the alternative-specific variables and the voter-specific variables as we do in our regressions.

${ }^{34}$ By doing that, we lose two additional observations corresponding to the two voters that did not solve more than 40 tables in the Baseline sessions, and for which we cannot compute the log of competence.
} 
Once we control for small and large differences in expected payoffs between the two candidates (Regressions 2 and 5), the coefficient for $\log$ (trustworthiness) becomes significantly larger than the coefficient for $\log$ (competence) for small differences $\left(\chi^{2}\right.$ test, $p=$ 0.079 for Regression 2, and 0.055 for Regression 5). In other words, for small differences in expected payoffs, we observe $\alpha_{1}>\alpha_{2}$, and, thus, we reject Hypothesis 3 in favor of some qualified support for Hypothesis 2.

Result 3. Subjects tended to weigh trustworthiness more than competence when the difference in expected profits between the two candidates was small enough, as predicted by Hypothesis 3, but, as the difference increased, people cared only about their expeted payoffs, as predicted by Hypothesis 1 .

This result also holds in Regressions 3 and 6 where we control for the demographic, psychological and behavioral characteristics of the subjects, and treatment effects from using the CIL method. In particular, for small differences in expected payoffs, the coefficient for $\log$ (trustworthiness) is almost twice as large as the coefficient for $\log$ (competence) and the difference is statistically significant $\left(\chi^{2}\right.$ test, $p=0.070$ for Regression 3, and 0.041 for Regression 6). ${ }^{35}$

So far we have assumed that subjects displayed adaptive expectations, that is they formed their expectations about how the potential public official will behave in the future based on the information provided to them regarding the past competence and trustworthiness of the candidates. It is possible that subjects displayed rational expectations. This means that the subjects' expectations about the future trustworthiness and competence of the public official matched exactly the true expected values of future trustworthiness and competence of the public official. In the online appendix, we replicate the analysis conducted so far by assuming that subjects display rational expectations. The results are qualitatively similar to those presented in the paper, if anything with stronger evidence of a trustworthiness bias. It might also be possible that our results are driven by extreme cases, namely situations where the difference in expected profits between the two candidates is very large. Hence, we replicate the analysis by dropping those cases. The results are reported in the online appendix and replicate those presented in the paper.

\footnotetext{
${ }^{35}$ Among the controls, the only coefficient (weakly) statistically significant is the interaction term between the CIL treatment and the log of trustworthiness (p-value $=0.070$ in Regression 6). In particular, subjects in the CIL sessions put a larger weight on trustworthiness compared to Baseline subjects.
} 


\section{Types classification}

We now classify the subjects of the CIL sessions based on their pattern of voting behavior. We can do so in the CIL sessions (and only in the CIL sessions) since in this treatment we collected multiple observations of voting behavior for each subject. We identify 6 categories of subjects, and Table 4 summarizes the results of this classification.

\section{[Table 4 about here]}

'Profit-maximizing' voters. These subjects always selected the more profitable candidate irrespectively of his or her competence and trustworthiness. In terms of our theoretical specification, the utility of the 'profit-maximizing' voters is characterized by $\alpha_{1}=\alpha_{2}>0$. In a first classification, we only consider those subjects who were profitmaximizing based on adaptive expectations. In a second classification, we also consider those subjects who were profit-maximizing based on rational expectations. ${ }^{36}$ Subjects that do not fall in the 'Profit-maximizing' subjects category are classified as follow.

'Unconditional competence' voters. These subjects always selected the more competent candidate irrespectively of the expected profits. The utility function of these subjects is characterized by $\alpha_{1}>0$ and $\alpha_{2}=0$.

'Unconditional trustworthiness' voters. These subjects always selected the more trustworthy candidate irrespectively of the expected profits. Their utility function is represented by $\alpha_{1}=0$ and $\alpha_{2}>0$.

'Conditional competence' voters. These subjects selected more often the competent candidate than the trustworthy candidate. ${ }^{37}$ The behavior of these subjects is captured by an utility function characterized by $\alpha_{2}>\alpha_{1}>0$.

\footnotetext{
${ }^{36} 50 \%$ of the subjects who are classified as profit-maximizing based on rational expectations, also fit in the category of the subjects who are profit-maximizing based on adaptive expectations.

${ }^{37}$ To identify these subjects, we computed, for each subject, the average vote for the trustworthy candidates when these were the least profitable, and compared it with the average vote for the competent candidates when these were the least profitable. If the difference was positive (i.e. the subject more often voted for the less profitable and trustworthy candidate than the less profitable and competent candidate), the subject was categorized as 'Conditional trustworthiness' subject. If the difference was negative (i.e. the subject more often voted for the less profitable and competent candidate than the less profitable and trustworthy candidate), the subject was categorized as 'Conditional competence' subject.
} 
'Conditional trustworthiness' voters. These subjects selected more often the trustworthy candidate than the competent candidate. The behavior of these subjects is captured by an utility function characterized by $\alpha_{1}>\alpha_{2}>0$.

'Profit-minimizing and Inconsistent' voters. These subjects tended to select the less profitable candidates or displayed a random voting behavior. This category includes the inconsistent subjects (i.e. subjects who selected the less profitable subjects when the latter was strictly or weakly dominated in both characteristics by the other candidate) and subjects who displayed a negative Spearman rank correlation coefficient between their voting decision and the difference in expected profits between the more and less profitable candidate (in other words, they display qualitatively the opposite pattern of the theoretical prediction of Figure 2). In terms of the parameters of the utility functions, the behavior of the profit-minimizing subjects is captured by $\alpha_{1}, \alpha_{2} \leq 0$.

Table 4 shows that the majority of voters displayed a profit-maximizing behavior. About a quarter of voters had a preference for the trustworthy candidate ('Unconditional and Conditional trustworthiness' voters), and possibly as little as $6 \%$ preferred a competent candidate ('Unconditional and Conditional competence' voters). ${ }^{38}$ This evidence provides additional support on what we presented earlier, that is most people tend to select the candidate rationally, based on who provides the highest expected profit irrespectively of trustworthiness and competence, but there is also a proportion of people who have a bias towards caring about trustworthiness. In terms of our theoretical specification, this means that the majority of the subjects present either a utility function characterized by $\alpha_{1}=\alpha_{2}>0$ or $\alpha_{1}>\alpha_{2}>0$. Obviously, this classification should be considered with caution and only as complement of the previous analysis as it is based on very few electoral situations per subject.

In this section the focus has been on the analysis of the subjects' voting behavior since this was the main objective of this paper. In the online appendix, we also analyze the behavior of the public officials in the third stage of the experiment.

\section{Discussion}

We investigated how voters weigh the competence and the trustworthiness of the candidates in public elections. We did so in a controlled environment which enabled us to

\footnotetext{
${ }^{38}$ Note that this does not mean that these voters did not care about expected payoffs. As shown by Table 3, sacrifices of payoffs often need to be small enough in order for the bias towards trustworthiness or competence to emerge.
} 
rule out all the other influences that may affect the electoral choices of voters. In particular, since, in our experiment, candidates differ only on their level of trustworthiness and competence, we are able to study the pure preferences of voters for trustworthiness and competence, and the extent to which they only care about what they expect to go in their pockets. By and large, we find that voters care about their expected payoffs and little else. In $84.4 \%$ of the cases, voters behaved rationally by selecting the candidate who was more expected to be profitable, based on their ex-ante trustworthiness and competence; the percentage becomes even higher $(87.9 \%)$ if we also include the cases described by rational expectations. A large majority of subjects always unfalteringly goes for the candidate that is expected to yield a higher payoff.

That said, around $25 \%$ of voters tend to be biased towards trustworthiness, and our regression analysis confirms a bias towards trustworthy candidates when the difference in expected profits between the two candidates is small enough. This holds irrespectively of whether we assume that voters display adaptive or rational expectations.

One could argue that the bias of the voters towards caring about trustworthiness that we observe in our experiment may not be the result of their preferences but of their misunderstanding of the instructions or systematic mistakes. ${ }^{39}$ This interpretation is not plausible for several reasons. First, we made sure that subjects understood the instructions by asking them to complete a computerized questionnaire before starting each task, where subjects had to solve some exercises and calculate the effects, in terms of payoffs, of their actions. Before the start of each task, subjects were invited to ask questions if something was not clear and clarifications were offered aloud to them if they had any doubts about the procedures and the calculation of the earnings. Second, our results show that subjects selected the more trustworthy but unprofitable candidate only under certain circumstances, that is when the difference in expected payoffs between the two candidates were small enough. If people failed to understand the instructions or the payoffs function, the bias would have characterized more generally all our data. ${ }^{40}$ Third, a lack of understanding or incentives would have resulted in random mistakes in both directions. This however was not the case as the bias occurred systematically in one direction. Fourth, in the data analysis, we controlled

\footnotetext{
${ }^{39}$ Subjects may have voted more often for the more trustworthy candidate either because they did not understand well the implications, in terms of payoffs, of their actions or because they committed more systematic mistakes when the difference in expected profits between the two candidates was small enough and the incentives to select the profitable candidate smaller.

${ }^{40}$ That, is we would have also observed the bias when the difference between the expected payoffs of the candidates was larger.
} 
for the behavior of those (few) inconsistent subjects who displayed a more random behavior and could have failed to understand the instructions or taken the experiment less seriously.

Another possible explanation of why subjects displayed a bias towards caring about trustworthiness may be related to the partially different nature of the trust game compared to the official's dilemma game. In particular, in the trust game, the trustee received an endowment from the truster as 'manna from heaven', whereas in the official's dilemma game the public official had to produce the endowment by counting 1s in tables. As a result, the measure of trustworthiness obtained in the trust game may have been different from the measure of trustworthiness obtained in the official's dilemma game. In particular, the trust game might have provided an inflated measure of trustworthiness compared to the official's dilemma game since, in the latter, voters might have felt more entitled to keep money for themselves as they had to work hard to produce the endowment. ${ }^{41}$ The data analysis however showed that the two measures were highly correlated, with the measure obtained in the trust game actually lower than the measure obtained in the official's dilemma game. And, as previously noted, the trustworthiness bias is replicated (if anything, it is slightly stronger) if we assume that voters held rational expectations rather than on adaptive expectations.

Another potential relevant confound concerns the state under which the decisions in the trust game and official's dilemma game respectively were taken. In particular, in the trust game, subjects decided 'in a cold state' as they did not know yet which role the computer assigned to them and under the presumption that the truster was going to trust them. In the official's dilemma game, the decision was more in a hot state as the public officials knew that trust was placed on them. As a result, the subjects may have been more sensitive to certain psychological pressures, such as trust responsiveness (Guerra and Zizzo, 2004) and reciprocity (Falk and Fischbacher, 2006), in the official's dilemma game than in the trust game, and, therefore, they may have fulfilled trust more in the official's dilemma game. If subjects anticipated that, they might have believed that the measure of trustworthiness provided to them was understated. As a result, they might have scaled up the information about the trustworthiness of the candidates provided to them. This however does not change

\footnotetext{
${ }^{41}$ Similar implications arise if subjects learned how to be untrustworthy in the trust game, and, in turn, displayed lower trustworthiness in the official's dilemma game. Note however that this type of learning could have also worked in the opposite direction: subjects learned how to be trustworthy in trust game, and, in turn, repaid trust more in the official's dilemma game.
} 
our results, since the voting choice that brings the highest utility is the same irrespectively of how utility is scaled (or the attributes are scaled). ${ }^{42}$

Another possible criticism of our experiment is that subjects were provided only with ex-ante measures of competence and trustworthiness which, from the standpoint of the subjects, may not necessarily capture the ex-post behavior of the public official. As a result, people may have formed certain beliefs about the ex-post competence and trustworthiness of the public official which could have not reflected the information provided to them during the voting phase. This is not however a problem as we found a very high correlation between early and later measures of trustworthiness and competence which would not justify such behavior unless subjects were extremely naïve. Second, and as previously discussed, we also analyzed the data assuming that the subjects had correct beliefs and predictions of the future behavior of the public official (rational expectations). ${ }^{43}$

Our experiment was conducted in the United Kingdom with subjects with a variety of different backgrounds. We do not find any differences, in our data, on how voters weigh the trustworthiness and competence of the candidates across the different nationalities of our subjects. This study is however not specifically designed to investigate cross-national differences. In particular, the number of observations that we collected for each country is relatively small, and, therefore, any definite conclusion would be too premature. Future research may wish to explore the extent to which our findings hold across different countries.

\section{Conclusions}

Our results show that voters tend mostly to care only about their final expected payoffs, irrespectively of the trustworthiness and competence of the candidates. These findings are useful to understand how voters decide in public elections. In particular, they

\footnotetext{
${ }^{42}$ To illustrate this, suppose that a voter $n$ believe that a unit of ex-ante trustworthiness is equivalent to $\tau$ units of ex-post trustworthiness. As long as this belief is the same for all the candidates (which is reasonable in our case since voters are only informed about the trustworthiness and competence of the candidates and nothing else), the voting choice of the voter does not change. More formally, the probability that voter $n$ chooses candidate $i$ is the same irrespectively of how the attributes are scaled:

$P_{n, i}=\operatorname{Prob}\left(U_{n, i}>U_{n, j}\right)=\operatorname{Prob}\left(U_{n, i}-U_{n, j}>0\right)=\operatorname{Prob}\left(A^{*}\left(\tau T_{n i}\right)^{\alpha_{1}}{C_{n i}}^{\alpha_{2}}-A^{*}\left(\tau T_{n j}\right)^{\alpha_{1}} C_{n j}{ }^{\alpha_{2}}>0\right)=$ $\operatorname{Prob}\left(A^{*} T_{n i}{ }^{\alpha_{1}} C_{n i}{ }^{\alpha_{2}}-A^{*} T_{n j}{ }^{\alpha_{1}} C_{n j}{ }^{\alpha_{2}}>0\right)$

In terms of our regression analysis, it means that the beliefs that change the scale of the attributes (trustworthiness and competence), do not change the estimation of the parameters $\alpha_{1}$ and $\alpha_{2}$.

${ }^{43}$ Also, as we have already mentioned earlier, the voting choice that brings the highest utility is the same irrespectively of how utility is scaled (or the attributes are scaled). This means that, as long as the beliefs of the voters change only the scale of the attributes of the candidates, our results do not change.
} 
support, in most of the cases, the idea that what ultimately matters for the voters is what they get in their pocket. Quoting James Carville's famous slogan, “[it is] the economy [that matters], stupid". As a result of this, voters may be willing to support untrustworthy candidates if the latter are perceived to contribute more to the overall welfare of the voters. This could explain why democracies may at times suffer from dishonesty and corruption at the public level.

We did identify a bias towards caring about trustworthiness, particularly when the candidates are similar in terms of their contribution to the financial welfare of the voters (that is, the difference in expected payoffs between the candidates is small enough). In these occasions, the information about the trustworthiness of the candidates can become crucial to determine which candidate will be elected, and so it is not just "the economy, stupid".

\section{References}

Abeler, J., A. Becker, and A. Falk. 2013. "Truth-Telling: A Representative Assessment". SSRN Scholarly Paper ID 2164648.

Abeler, J., A. Falk, L. Goette, and D. Huffman. 2011. "Reference Points and Effort Provision." The American Economic Review. 101 (2): 470-492.

Arbak, E., and M-C. Villeval. 2013. "Voluntary Leadership: Motivation and Influence." Social Choice and Welfare, 40 (3): 635-662.

Azfar, O., and W. R. Nelson Jr. 2007. "Transparency, Wages, and the Separation of Powers: An Experimental Analysis of Corruption." Public Choice, 130 (3-4): 471-493.

Bågenholm, A. 2013. "Throwing the Rascals Out? The Electoral Effects of Corruption Allegations and Corruption Scandals in Europe 1981-2011." Crime, Law and Social Change, $60(5): 1-15$.

Bardsley, N. 2000. "Control Without Deception: Individual Behaviour in Free-Riding Experiments Revisited." Experimental Economics, 3 (3): 215-240.

Barr, A., M. Lindelow, and P. Serneels. 2009. "Corruption in Public Service Delivery: An Experimental Analysis." Journal of Economic Behavior and Organization. 72 (1): 225-239.

Bartlett, J. 2013. "How Beppe Grillo's social media politics took Italy by storm". theguardian.com, 26 February. Available online at http://www.theguardian.com/ 
commentisfree/2013/feb/26/beppe-grillo-politics-social-media-italy (accessed 27 February 2014).

Berg, J., J. Dickhaut, and K. McCabe. 1995. "Trust, Reciprocity, and Social History.” Games and Economic Behavior, 10 (1): 122-142.

Bohnet, I., F. Greig, B. Herrmann, and R. Zeckhauser. 2008. "Betrayal Aversion: Evidence from Brazil, China, Oman, Switzerland, Turkey, and the United States." The American Economic Review, 98 (1): 294-310.

Brandts, J., D. J. Cooper, and R. Weber. 2013. "Legitimacy, Social Distance, and Leadership in the Turnaround Game." Working Paper.

Bucciol, A., and M. Piovesan. 2011. "Luck or Cheating? A Field Experiment on Honesty with Children.” Journal of Economic Psychology, 32 (1): 73-78.

Caselli, F., and M. Morelli. 2004. "Bad Politicians." Journal of Public Economics, 88 (3-4): 759-782.

Christie, R., F. L. Geis, and D. Berger. 1970. Studies in Machiavellianism. New York: Academic Press.

Corazzini, L., S. Kube, M. A. Maréchal, and A. Nicolo. 2013. "Elections and Deceptions: An Experimental Study on the Behavioral Effects of Democracy". SSRN Scholarly Paper ID 1430904.

Croson, R. T. A. 2005. "Deception in Economics Experiments." In C. Gerschlager (Ed.), Deception in Markets: An Economic Analysis, Basingstoke: Palgrave Macmillan.

DeMaio, T. J. 1984. Social Desirability and Survey Measurement: A Review. New York: Russell Sage Foundation.

Eckel, C. C., P. J. Grossman, C. A. Johnson, A. C. M. de Oliveira, C. Rojas, and R. K. Wilson. 2012. "School Environment and Risk Preferences: Experimental Evidence.” Journal of Risk and Uncertainty, 45 (3): 265-292.

Eggers, A., and A. C. Fisher. 2011. "Electoral Accountability and the UK Parliamentary Expenses Scandal: Did Voters Punish Corrupt MPs?” SSRN Scholarly Paper ID 1931868. 
Falk, A., and U. Fischbacher. 2006. "A Theory of Reciprocity." Games and Economic Behavior, 54 (2): 293-315.

Ferraz, C., and F. Finan. 2008. "Exposing Corrupt Politicians: The Effects of Brazil's Publicly Released Audits on Electoral Outcomes." The Quarterly Journal of Economics, 123 (2): 703-745.

Fischbacher, U. 2007. "z-Tree: Zurich Toolbox for Ready-made Economic Experiments." Experimental Economics, 10 (2): 171-178.

Fischbacher, U., and F. Föllmi-Heusi. 2013. "Lies in Disguise-an Experimental Study on Cheating." Journal of the European Economic Association, 11 (3): 525-547.

Gächter, S., and E. Renner. 2005. "Leading by Example in the Presence of Free Rider Incentives." CeDEx Discussion Paper, University of Nottingham.

Gächter, S., D. Nosenzo, E. Renner, and M. Sefton. 2012. "Who Makes a Good Leader? Cooperativeness, Optimism, and Leading-by-Example.” Economic Inquiry, 50 (4): 953-967.

Gneezy, U. 2005. "Deception: The Role of Consequences." The American Economic Review, 95 (1): 384-394.

Greiner, B. 2004. “An Online Recruitment System for Economic Experiments”. MPRA Paper.

Guerra, G., and D. J. Zizzo. 2004. "Trust Responsiveness and Beliefs." Journal of Economic Behavior and Organization, 55 (1): 25-30.

Güth, W., M. V. Levati, M. Sutter, and E. van der Heijden. 2007. "Leading by Example with and Without Exclusion Power in Voluntary Contribution Experiments." Journal of Public Economics, 91 (5-6): 1023-1042.

Hamman, J. R., R. A. Weber, and J. Woon. 2011. “An Experimental Investigation of Electoral Delegation and the Provision of Public Goods." American Journal of Political Science, 55 (4): 738-752.

Hao, L., and D. Houser. 2013. "Perceptions, Intentions, and Cheating”. Working Paper 1039, George Mason University, Interdisciplinary Center for Economic Science.

Houser, D., S. Vetter, and J. Winter. 2012. "Fairness and Cheating." European Economic Review, 56 (8): 1645-1655. 
Kocher, M. G., G. Pogrebna, and M. Sutter. 2013. "Other-regarding Preferences and Management Styles.” Journal of Economic Behavior and Organization, 88: 109-132.

Kulisheck, M. R, and J. J Mondak. 1996. "Candidate Quality and the Congressional Vote: A Causal Connection?” Electoral Studies, 15 (2): 237-253.

Kumru, C. S., and L. Vesterlund. 2010. "The Effect of Status on Charitable Giving." Journal of Public Economic Theory, 12 (4): 709-735.

Levy, D. M., K. Padgitt, S. J. Peart, D. Houser, and E. Xiao. 2011. "Leadership, Cheap Talk and Really Cheap Talk.” Journal of Economic Behavior and Organization, 77 (1): 40-52.

Lodge, M., P. Stroh, and J. Wahlke. 1990. "Black-box Models of Candidate Evaluation." Political Behavior, 12 (1): 5-18.

Marquardt, D.W., 1980. "You Should Standardize the Predictor Variables in Your Regression Models." Journal of the American Statistical Association, 75 (369): 87-91.

Mas-Colell, A., M. D. Whinston, and J. R. Green. 1995. Microeconomic theory. Vol. 1. New York: Oxford university press.

Mazar, N., and D. Ariely. 2006. "Dishonesty in Everyday Life and Its Policy Implications." Journal of Public Policy and Marketing, 25 (1): 117-126.

McCurley, C., and J. J. Mondak. 1995. "Inspected by \#1184063113: The Influence of Incumbents' Competence and Integrity in U.S. House Elections." American Journal of Political Science, 39 (4): 864.

Messick, D. M., H. Wilke, M. B. Brewer, R. M. Kramer, P. E. Zemke, and L. Lui. 1983. "Individual Adaptations and Structural Change as Solutions to Social Dilemmas." Journal of Personality and Social Psychology, 44 (2): 294-309.

Mondak, J. J. 1995. "Competence, Integrity, and the Electoral Success of Congressional Incumbents." The Journal of Politics, 57 (04): 1043-1069.

Mondak, J. J., and R. Huckfeldt. 2006. "The Accessibility and Utility of Candidate Character in Electoral Decision Making." Electoral Studies, 25 (1): 20-34.

Moxnes, E., and E. van der Heijden. 2003. "The Effect of Leadership in a Public Bad Experiment." Journal of Conflict Resolution, 47 (6): 773-795. 
Peters, J. G., and S. Welch. 1980. "The Effects of Charges of Corruption on Voting Behavior in Congressional Elections." The American Political Science Review, 74 (3): 697.

Pokorny, K. 2008. "Pay—but Do Not Pay Too Much: An Experimental Study on the Impact of Incentives.” Journal of Economic Behavior and Organization, 66 (2): 251-264.

Potters, J., M. Sefton, and L. Vesterlund. 2007. "Leading-by-example and Signaling in Voluntary Contribution Games: An Experimental Study." Economic Theory, 33 (1): 169-182.

Rabin, M. 1993. "Incorporating Fairness into Game Theory and Economics." The American Economic Review, 83 (5): 1281-1302.

Rivas, M. F., and M. Sutter. 2011. "The Benefits of Voluntary Leadership in Experimental Public Goods Games.” Economics Letters, 112 (2): 176-178.

Samuelson, C. D, and D. M. Messick. 1986. "Alternative Structural Solutions to Resource Dilemmas." Organizational Behavior and Human Decision Processes, 37 (1): 139-155.

Samuelson, C. D., D. M. Messick, C. Rutte, and H. Wilke. 1984. "Individual and Structural Solutions to Resource Dilemmas in Two Cultures." Journal of Personality and Social Psychology, 47 (1): 94-104.

Shampanier, K., N. Mazar, and D. Ariely. 2007. "Zero as a Special Price: The True Value of Free Products.” Marketing Science, 26 (6): 742-757.

Stöber, J. 2001. "The Social Desirability Scale-17 (SDS-17): Convergent Validity, Discriminant Validity, and Relationship with Age." European Journal of Psychological Assessment, 17 (3): 222-232.

Sutter, M. 2009. "Deception Through Telling the Truth?! Experimental Evidence From Individuals and Teams." The Economic Journal, 119 (534): 47-60.

Welch, S., and J. R. Hibbing. 1997. "The Effects of Charges of Corruption on Voting Behavior in Congressional Elections, 1982-1990." The Journal of Politics, 59 (01): 226-239.

Winters, M. S., and R. Weitz-Shapiro. 2013. "Lacking Information or Condoning Corruption: When Do Voters Support Corrupt Politicians?" Comparative Politics, 45 (4): 418-436. 


\section{Figures and Tables}

Figure 1: Probability that a candidate $i$ is elected

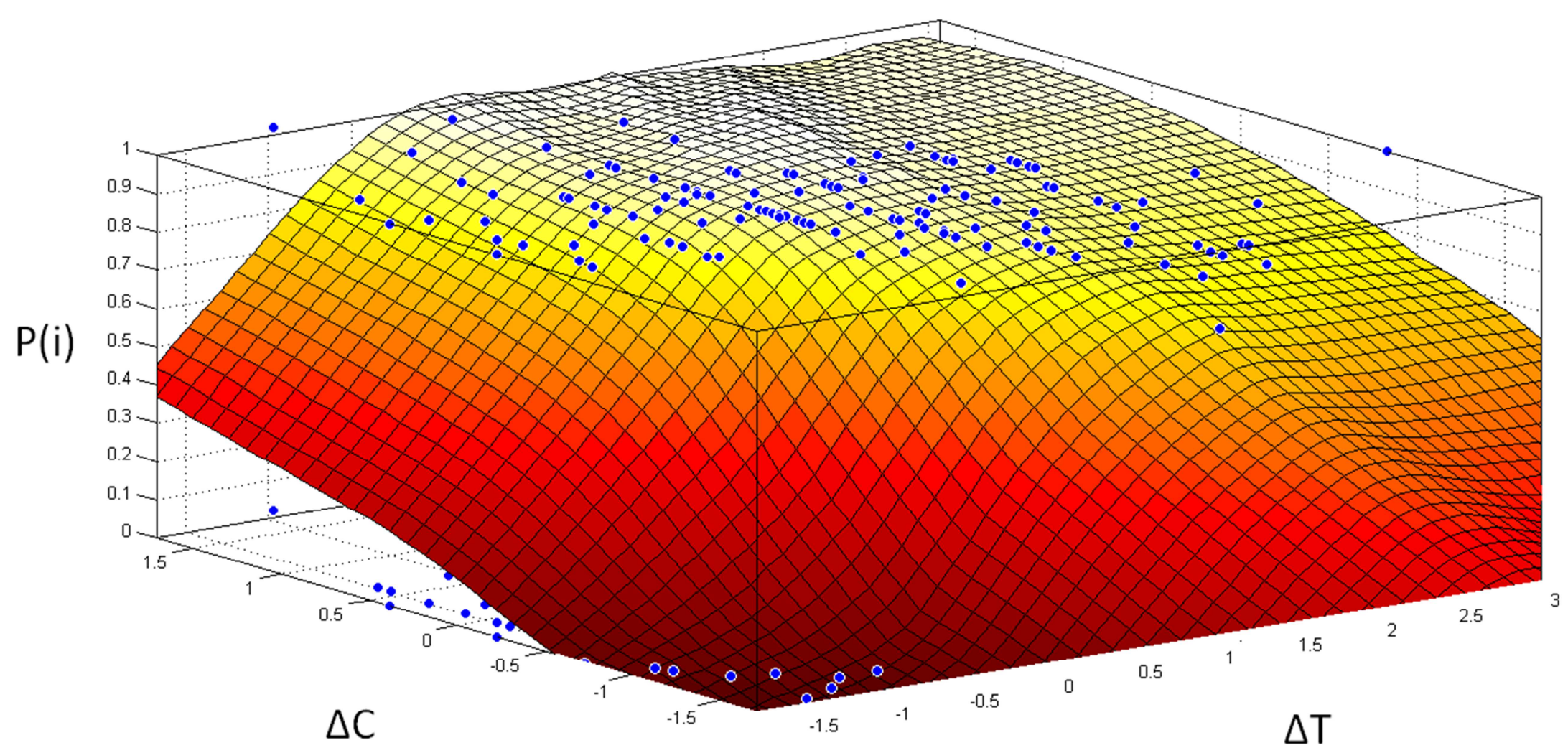

Notes: $\mathrm{P}(\mathrm{i})$ is the probability of electing a candidate $i$ in election $k$. This is computed using a locally weighted linear regression on the dichotomous variable taking value 1 when the candidate $i$ is elected and 0 otherwise. $\Delta \mathrm{C}$ is the difference in standardized competence between candidate $i$ and candidate $j$ in the situation (election) $k$. $\Delta \mathrm{T}$ is the difference in standardized trustworthiness between candidate $i$ and candidate $j$ in the situation (election) $k$. The standardized values are obtained by subtracting the mean and dividing by the standard deviation. Each smoothed value of the locally weighted surface is computed using neighboring data points defined within the span of 0.6 (60\% of the data). 
Figure 2: Probability of electing the more trustworthy candidate

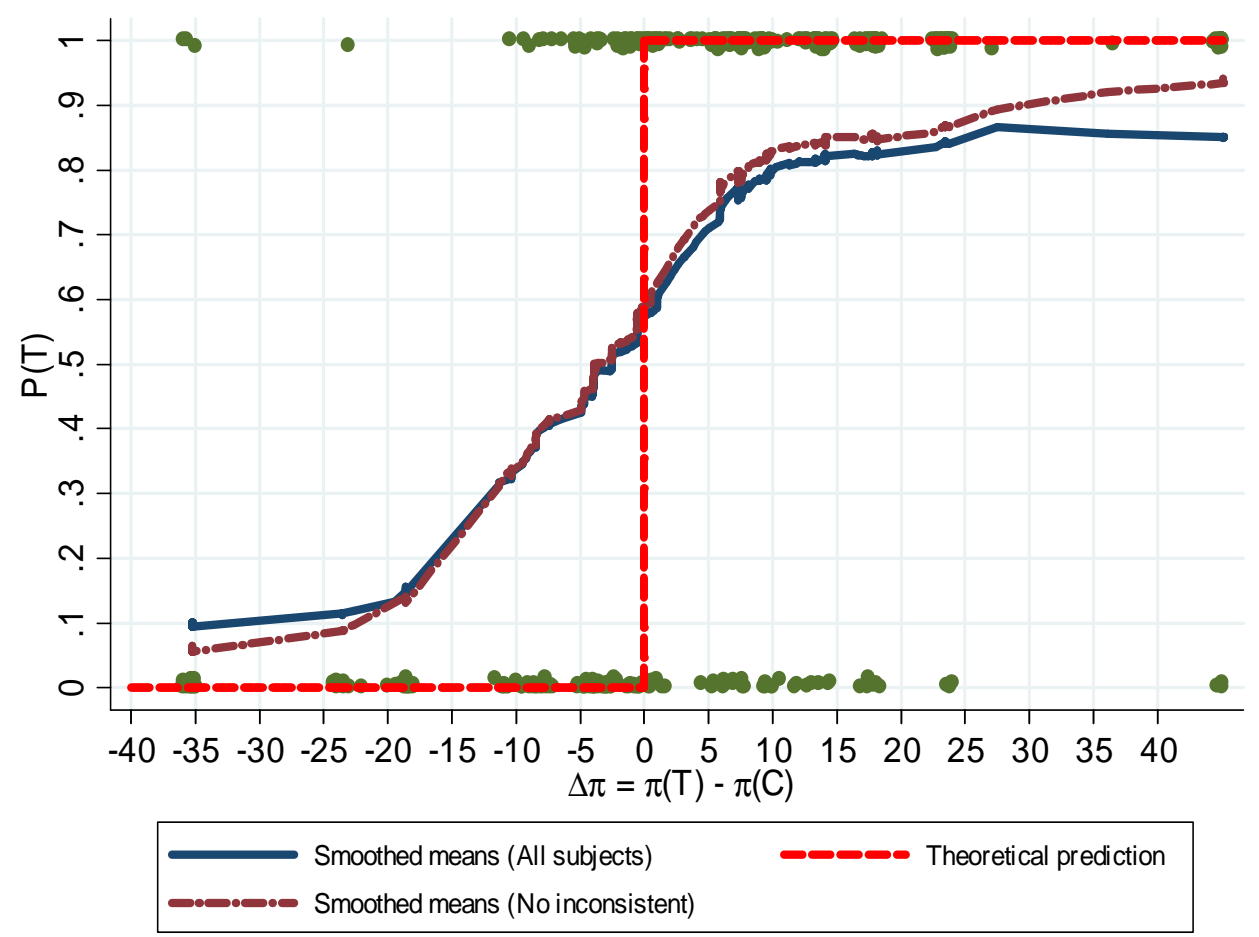

Notes: $\mathrm{P}(\mathrm{T})$ is the probability of electing the more trustworthy candidate. $\Delta \pi$ is the difference in expected payoffs between the more and less trustworthy candidate. The running means are weighted to give more importance to near points than far, and computed using a bandwith of 0.6 (60\% of the data). The data correspond to cases where there was a trade-off between trustworthiness and competence.

Figure 3: Proportion of cases where the less profitable candidate was voted

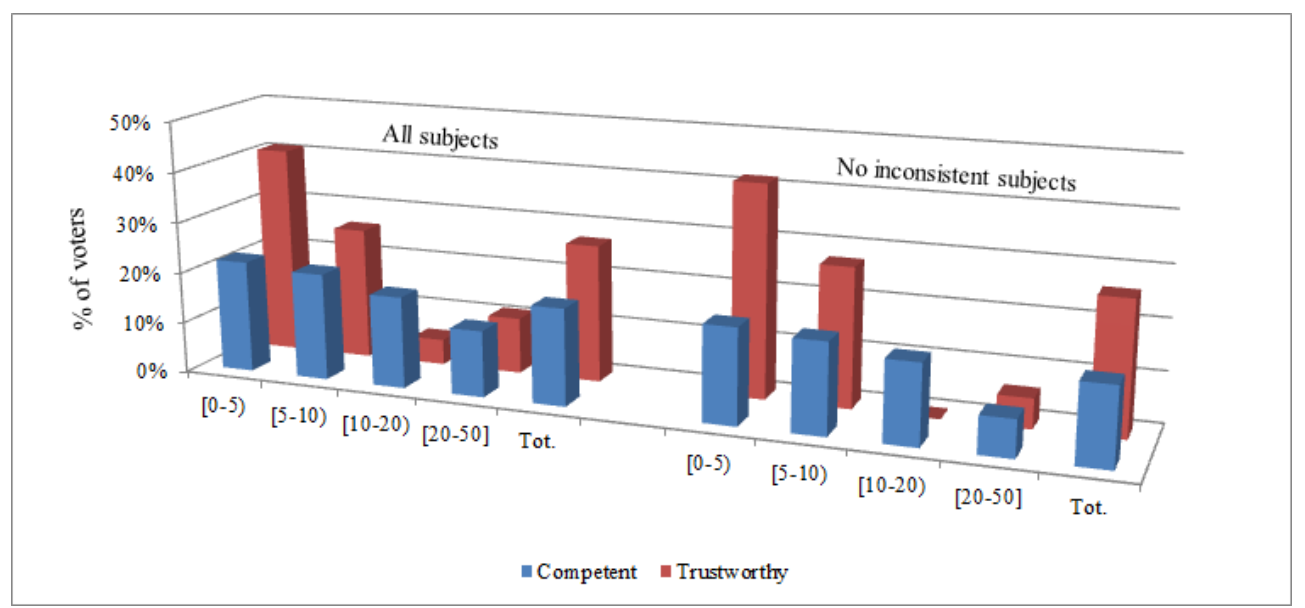

Notes: The red bar identifies the proportion of cases where the voters elected the more trustworthy candidate when the latter was the less profitable one. The blue bar identifies the proportion of cases where the voters elected the more competent candidate when the latter was the less profitable one. The intervals in the $\mathrm{x}$-axis are in experimental points. The data correspond to cases where there was a trade-off between trustworthiness and competence. 
Table 1: Competence and Trustworthiness

\begin{tabular}{cccccc}
\hline \hline & \multicolumn{2}{c}{ Competence } & & \multicolumn{2}{c}{ Trustworthiness } \\
\cline { 2 - 3 } \cline { 6 - 6 } & Mean & St. Dev. & & Mean & St. Dev. \\
\hline Real effort task stage first & 39.49 & 17.75 & & 0.36 & 0.19 \\
Trust game stage first & 35.43 & 16.97 & & 0.34 & 0.17 \\
Total & 37.46 & 17.44 & & 0.35 & 0.18 \\
\hline
\end{tabular}

Table 2: Voting choices

\begin{tabular}{cccccc}
\hline \hline Situation & Trustworthiness & Competence & Votes for $\boldsymbol{i}$ & Votes for $\boldsymbol{j}$ & Tot. \\
\hline Strict dominance & $\mathrm{Ti}>\mathrm{Tj}$ & $\mathrm{Ci}>\mathrm{Cj}$ & 160 & 10 & 170 \\
Trade-off & $\mathrm{Ti}>\mathrm{Tj}$ & $\mathrm{Ci}<\mathrm{Cj}$ & 238 & 163 & 401 \\
Weak dominance & $\mathrm{Ti}=\mathrm{Tj}$ & $\mathrm{Ci} \geq \mathrm{Cj}$ & 86 & 4 & 90 \\
Weak dominance & $\mathrm{Ti} \geq \mathrm{Tj}$ & $\mathrm{Ci}=\mathrm{Cj}$ & 8 & 2 & 10 \\
Equality & $\mathrm{Ti}=\mathrm{Tj}$ & $\mathrm{Ci}=\mathrm{Cj}$ & 0 & 1 & 1 \\
\hline Total &. &. & 492 & 180 & 672 \\
\hline
\end{tabular}


Table 3: Alternative-specific conditional logit regressions

\begin{tabular}{|c|c|c|c|c|c|c|}
\hline & \multicolumn{2}{|c|}{ Regression 1} & \multicolumn{2}{|c|}{ Regression 2} & \multicolumn{2}{|c|}{ Regression 3} \\
\hline & $\mathrm{b}$ & se & $\mathrm{b}$ & $\mathrm{Se}$ & $\mathrm{b}$ & se \\
\hline $\log$ (Trustworthiness) & $1.47 * * *$ & 0.25 & $3.69 * * *$ & 1.11 & $4.38 * * *$ & 1.31 \\
\hline $\log ($ Competence $)$ & $1.46 * * *$ & 0.23 & $2.82 * * *$ & 0.82 & $2.76^{* *}$ & 1.2 \\
\hline $\log ($ Trustworthiness $) \times|\pi|>5$ & & & $-2.29 * *$ & 1.03 & $-2.49 * *$ & 1.08 \\
\hline $\log ($ Competence $) \times|\pi|>5$ & & & -1.24 & 0.79 & $-1.61 * *$ & 0.81 \\
\hline $\begin{array}{l}\text { Interactions with } \\
\text { demographic, behavioral, } \\
\text { psychological and treatment } \\
\text { variables }\end{array}$ & \multicolumn{2}{|l|}{ No } & \multicolumn{2}{|l|}{ No } & \multicolumn{2}{|c|}{ Yes } \\
\hline Obs & 778 & & 778 & & 776 & \\
\hline Pseudo $\mathrm{R}^{2}$ & 0.25 & & 0.26 & & 0.31 & \\
\hline Df & 2 & & 4 & & 30 & \\
\hline \multirow[t]{3}{*}{ Prob $>$ F } & 0 & & 0 & & 0 & \\
\hline & \multicolumn{2}{|c|}{ Regression 4} & \multicolumn{2}{|c|}{ Regression 5} & \multicolumn{2}{|c|}{ Regression 6} \\
\hline & $\mathrm{b}$ & se & $\mathrm{b}$ & $\mathrm{Se}$ & $\mathrm{b}$ & se \\
\hline $\log ($ Trustworthiness $)$ & $1.90 * * *$ & 0.29 & $3.88 * * *$ & 1.12 & $5.20 * * *$ & 1.59 \\
\hline $\log ($ Competence $)$ & $1.76 * * *$ & 0.27 & $2.91 * * *$ & 0.82 & $2.98 * *$ & 1.21 \\
\hline $\begin{array}{l}\log (\text { Trustworthiness }) \times \\
\text { Inconsistency }\end{array}$ & $-1.94 * * *$ & 0.46 & $-1.87 * * *$ & 0.45 & $-2.89 * * *$ & 0.56 \\
\hline $\begin{array}{l}\log (\text { Competence }) \times \\
\text { Inconsistency }\end{array}$ & $-1.17^{*}$ & 0.61 & -1.13 & 0.69 & $-1.49 * *$ & 0.68 \\
\hline $\log ($ Trustworthiness $) \times|\pi|>5$ & & & $-2.06^{*}$ & 1.06 & $-2.37 * *$ & 1.18 \\
\hline $\log ($ Competence $) \times|\pi|>5$ & & & -1.02 & 0.81 & $-1.46^{*}$ & 0.86 \\
\hline $\begin{array}{c}\text { Interactions with } \\
\text { demographic, behavioral, } \\
\text { psychological and treatment } \\
\text { variables }\end{array}$ & \multicolumn{2}{|l|}{ No } & \multicolumn{2}{|l|}{ No } & \multicolumn{2}{|c|}{ Yes } \\
\hline Obs & \multicolumn{2}{|l|}{778} & \multicolumn{2}{|l|}{778} & \multicolumn{2}{|l|}{776} \\
\hline Pseudo $\mathrm{R}^{2}$ & \multicolumn{2}{|l|}{0.3} & \multicolumn{2}{|l|}{0.32} & \multicolumn{2}{|l|}{0.38} \\
\hline Df & \multicolumn{2}{|l|}{4} & \multicolumn{2}{|l|}{6} & \multicolumn{2}{|l|}{32} \\
\hline Prob $>$ F & \multicolumn{2}{|l|}{0} & \multicolumn{2}{|l|}{0} & \multicolumn{2}{|l|}{0} \\
\hline
\end{tabular}

Notes: Alternative-specific logit regression with robust standard errors clustered at individual level. The table reports the beta coefficients and the standard errors. The demographic variables are age, gender (= 1 for men), economics background (= 1 if applicable), nationality (UK $=1$ for UK subjects, and China $=1$ for Chinese subjects), and University status (= 1 for undergraduate students). The behavioral variables are the competence and trustworthiness of the voter. The psychological variables are the risk attitude, the SDS17 score and MACH score. The treatment variables are the CIL sessions, and the sessions where the trust game stage took place before the real effort task stage. The psychological and behavioral variables and age are centered at the mean in order to control for high correlation between the independent variables (see Marquardt, 1980). 'China' identifies subjects from China, Taiwan or Hong Kong. The data correspond to cases where there was a trade-off between trustworthiness and competence. The full regressions are in the online appendix. $* p<0.1, * * p<0.05$, *** $p<$ 0.01 . 
Table 4: Subjects' classification based on their voting behavior

\begin{tabular}{|c|c|c|c|}
\hline Type & Utility & $\%(\omega)$ & $\%(\omega)$ \\
\hline Unconditional competence & $\begin{array}{l}\alpha_{1}=0 \\
\alpha_{2}>0\end{array}$ & $6.94 \%(5)$ & $2.78 \%(2)$ \\
\hline Unconditional trustworthiness & $\begin{array}{l}\alpha_{1}>0 \\
\alpha_{2}=0\end{array}$ & $8.33 \%(6)$ & $8.33 \%(6)$ \\
\hline Conditional competence & $\begin{array}{l}\alpha_{2}>\alpha_{1} \\
\alpha_{1,2}>0\end{array}$ & $8.33 \%(6)$ & $2.78 \%(2)$ \\
\hline Conditional trustworthiness & $\begin{array}{l}\alpha_{1}>\alpha_{2} \\
\alpha_{1,2}>0\end{array}$ & $18.06 \%(13)$ & $18.06 \%(13)$ \\
\hline Profit maximizing (adaptive expectations) & $\begin{array}{l}\alpha_{1}=\alpha_{2} \\
\alpha_{1,2}>0\end{array}$ & $44.44 \%(32)$ & $34.72 \%(25)$ \\
\hline Profit maximizing (rational expectations) & $\begin{array}{l}\alpha_{1}=\alpha_{2} \\
\alpha_{1,2}>0\end{array}$ & & $19.44 \%(14)$ \\
\hline Profit minimizing and Inconsistent & $\alpha_{1,2} \leq 0$ & $13.89 \%(10)$ & $13.89 \%(10)$ \\
\hline Total & & $100 \%(72)$ & $100 \%(72)$ \\
\hline
\end{tabular}




\section{Competence versus Trustworthiness: What Do Voters Care About?}

\section{By Fabio Galeotti and Daniel John Zizzo}

\section{Online Appendix}
A. Experimental instructions
B. Final questionnaire
C. Background information on participants
D. Full regressions of Table 4
E. Analysis with rational expectations
F. Analysis without outliers
G. Analysis of the public officials' behavior
H. Additional analysis of behavior in stages 1 and 2

\section{A. Experimental instructions}

- Baseline (in half of the sessions, the order of stage 1 and stage 2 was inverted)

\section{Instructions}

\section{$\underline{\text { Introduction }}$}

This is an experiment on decision making. The instructions are the same for all participants. During the experiment, you are not allowed to communicate with other participants. Please raise your hand if you have any questions at any point during the experiment. If you have any questions, the experimenter will come to you and answer your questions privately. If the question is relevant to everyone, the experimenter will repeat the answer aloud.

The experiment consists of three stages. In addition to these three stages, you will be asked some individual questions at the end of the experiment. At the beginning of each stage you will receive the corresponding instructions. The information you provide in each stage of the experiment may be reported to other participants at later stages of the experiment. However, all of your decisions and answers will remain anonymous.

During this experiment, your earnings depend on your decisions and the decisions of the other participants. It is therefore important that you read the instructions with care. Your earnings from the experiment will be computed in "points".

At the end of the experiment one stage will be chosen at random, and you will be paid the points that you earned in that stage. The points that you earn in that stage will be converted into pounds at an exchange rate of 1 point $=20$ pence. In addition to this, you will also be paid a show-up fee of 2 pounds and any additional earnings that you may obtain by 
answering the questions at the end of the experiment. You will be paid individually and in cash in a separate room by a person who is not present during the experiment and who is not aware of the content of this experiment.

\section{First stage}

In this stage of the experiment your task will be to count the number of $1 \mathrm{~s}$ in a series of tables containing $0 \mathrm{~s}$ and $1 \mathrm{~s}$. The figure shows the kind of screen you will see later:

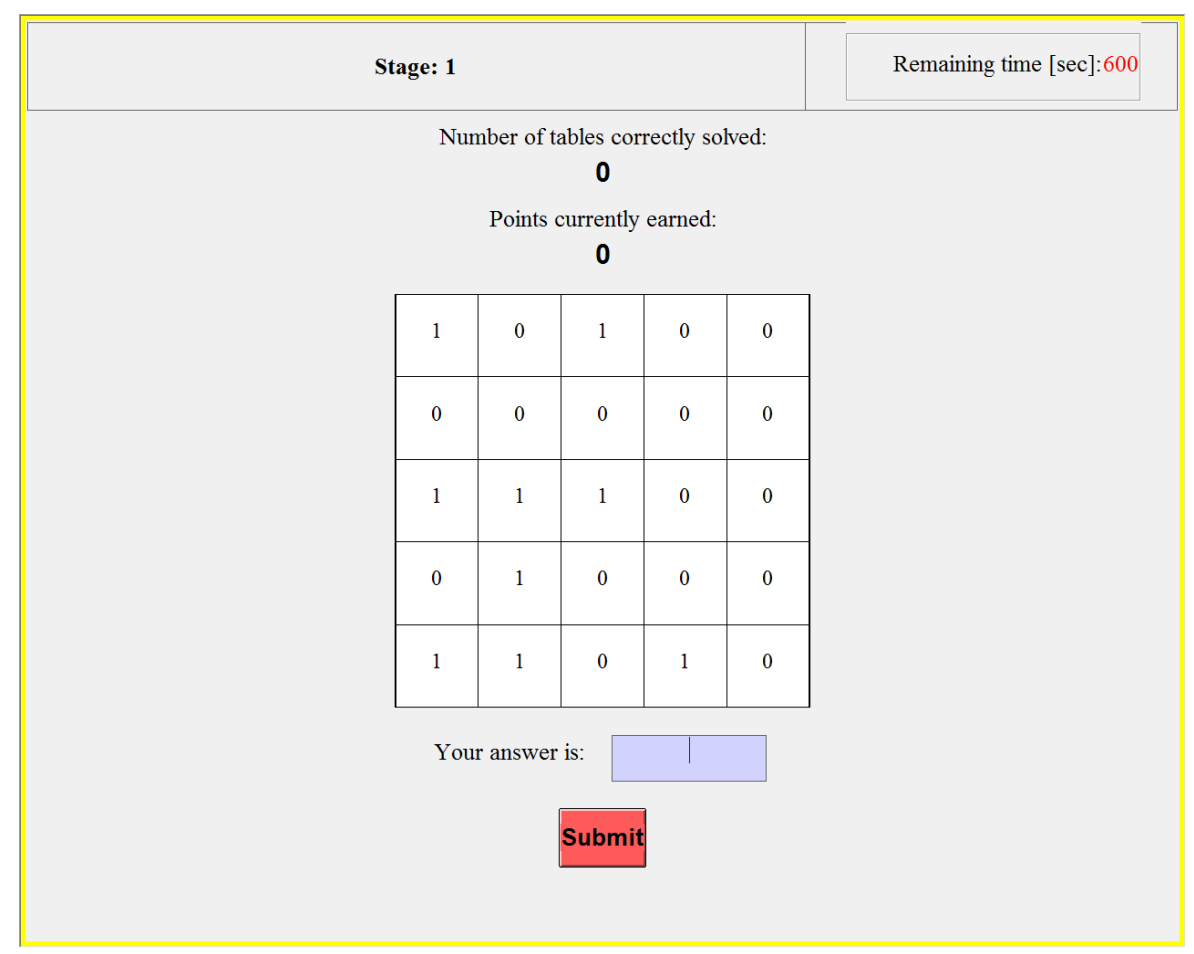

You will have to enter the number of 1s into the box below the table and click the Submit button. After you have submitted your answer, a new table will be generated.

You will only earn money after correctly solving 40 tables. Specifically, you will receive 1 point for each table you correctly solve on top of the first 40 correctly solved tables. The greater the number of tables you solve correctly over and above the first 40 correctly solved tables, the more points you will earn.

You will have 10 minutes to complete the first stage of the experiment. Your remaining time will be displayed in the upper right hand corner of the screen.

\section{Second stage}

In this stage of the experiment, you will be matched at random with another participant. You will never interact with this person again in the remainder of the experiment. One of the two will be randomly assigned the role of participant $\mathbf{A}$, and the other the role of participant $\mathbf{B}$.

Participant A will receive an endowment of $\mathbf{3 0}$ points. He or she will decide whether or not to transfer all the 30 points to participant $\mathrm{B}$. There are two scenarios: 
1. If participant $\mathrm{A}$ decides not to transfer the 30 points to participant $\mathrm{B}$, participant $\mathrm{A}$ will earn 30 points and participant B 0 points.

2. If participant $\mathrm{A}$ decides to transfer the 30 points to participant $\mathrm{B}$, these points get multiplied by 3 before they are received by participant B. Hence, participant B will receive 90 points overall. Participant $B$ then will decide how many points to keep and how many points to return to participant A. Specifically, he/she can return to participant A any amount between a minimum of 9 points to a maximum of 90 points.

You will be informed about your role (participant A or B) only at the end of the experiment. Hence, at this stage, you will have to make decisions in the roles of both participant A and participant B:

- As participant A, you will have to decide if you want to transfer the 30 points or not to participant $\mathrm{B}$.

- As participant B, you will make a decision without knowing if participant A has chosen to transfer or not the 30 points to you. Specifically, you will have to decide how many points you would wish to return to participant A if participant A were to transfer his or her 30 points to you.

At the end of this stage, if participant $A$ has chosen not to transfer the 30 points, participant B's decision will be ignored and earnings will be 30 points for participant A and 0 for participant $B$. If participant $A$ has chosen to transfer the 30 points, participant B's decision will determine the earnings of both participants.

The results and earnings for this stage will be communicated to you at the end of the experiment and will depend on the role that you have been assigned to.

\section{Third stage}

The task in this stage of the experiment is to count $1 \mathrm{~s}$ in a series of tables as in the first stage of the experiment. However, new rules are now in effect, which did not apply in the first stage.

Specifically, you will be randomly matched with two other participants you have never been matched with before. You and these two participants will now be referred to as coparticipants. The three of you will have a common fund. At the beginning of the task, the value of the common fund will be set to 0 points. Every co-participant will individually work on the task for 10 minutes (the remaining time will be displayed in the upper right hand corner of the work screen). However, only one co-participant's work will count for the earnings of this stage of the experiment. This co-participant will be referred to as the appointed co-participant. After the appointed co-participant correctly solves 40 tables, each additional correct answer of the appointed co-participant will increase the value of the common fund by 4 points. 
At the end of the task, the common fund will have accumulated a certain number of points equal to four times the number of tables that the appointed co-participant correctly solved on top of the first 40 correctly solved tables. Only the appointed co-participant will know the number of tables that he or she correctly solved (and so the value of the common fund). He or she will be asked to report the value of the common fund to the other co-participants. He or she can report any number between 0 and the true value of the common fund. This number corresponds to the reported value of the common fund. The reported value of the common fund will be split equally between the co-participants. That is, each co-participant (including the appointed co-participant) will receive $1 / 3$ of the reported value of the common fund. If applicable, the appointed co-participant will also earn the whole of the non-reported value of the common fund, that is the value of the common fund not reported. Note that the appointed co-participant will be free to report or not the true value of the common fund. Moreover, the other co-participants will only be informed of the reported value of the common fund.

Example: Suppose the appointed co-participant solves 52 tables correctly (hence 12 tables over and above 40 correctly solved tables); the value of the common fund is $12 \times 4=48$. The appointed co-participant however reports a value of 33 . The non-reported value of the common fund is $48-33=15$. The earnings are therefore:

- 33 / 3 = 11 for each non-appointed co-participant;

- $33 / 3+15=26$ for the appointed co-participant.

How is the appointed co-participant selected? Before starting the task, each co-participant will be informed of:

- the number of tables correctly solved by each other co-participant in the first stage of the experiment where the task was to count $1 \mathrm{~s}$ in tables;

- the proportion of points that each other co-participant in the role of participant B returned to participant $\mathrm{A}$ in the second stage of the experiment.

Each co-participant will then be asked to choose which of the two other co-participants he or she would like to select as the appointed co-participant. The decision of one randomly selected co-participant will be implemented. Hence, it is in your best interest to choose the co-participant that you really want as the appointed co-participant.

Afterwards, the computer will inform each co-participant whether or not he or she is the appointed co-participant. Then the task of counting $1 \mathrm{~s}$ in a series of tables will start.

\section{In summary}

- You will be randomly matched with two other participants you have never been matched with before. You and these two participants will be referred to as coparticipants. The three of you will have a common fund with an initial value of 0 points. 
- Each co-participant will choose whom he or she wants to select as appointed coparticipant between the other two co-participants. The decision of one co-participant selected at random will be implemented.

- Everyone will work for 10 minutes on the task which consists in counting $1 \mathrm{~s}$ in a series of tables containing $0 \mathrm{~s}$ and $1 \mathrm{~s}$. However, only the work of the appointed coparticipant will count for the earnings. Specifically, for each table that the appointed co-participant correctly solves on top of the first 40 correctly solved tables, the value of the common fund increases by 4 points.

- At the end of the task the appointed co-participant can report any number between 0 and the true value of the common fund to the other co-participants. This number constitutes the reported value of the common fund. The other co-participants will be informed only about the reported value of the common fund.

- The reported value of the common fund will be divided in equal parts (each worth $1 / 3$ of the reported value) between the co-participants (including the appointed coparticipant). If applicable, the appointed co-participant will also earn the whole of the non-reported value of the common fund, that is the value of common fund not reported.

- Stage 3 of CIL treatment

\section{Third stage}

The task in this stage of the experiment is to count $1 \mathrm{~s}$ in a series of tables as in the first stage of the experiment. However, new rules are now in effect, which did not apply in the first stage.

Specifically, you will be randomly matched with two other participants you have never been matched with before. You and these two participants will now be referred to as coparticipants. The three of you will have a common fund. At the beginning of the task, the value of the common fund will be set to 0 points. Every co-participant will individually work on the task for 10 minutes (the remaining time will be displayed in the upper right hand corner of the work screen). However, only one co-participant's work will count for the earnings of this stage of the experiment. This co-participant will be referred to as the appointed co-participant. After the appointed co-participant correctly solves 40 tables, each additional correct answer of the appointed co-participant will increase the value of the common fund by $\mathbf{4}$ points.

At the end of the task, the common fund will have accumulated a certain number of points equal to four times the number of tables that the appointed co-participant correctly solved on top of the first 40 correctly solved tables. Only the appointed co-participant will know the number of tables that he or she correctly solved (and so the value of the common fund). He or she will be asked to report the value of the common fund to the other co-participants. He or she can report any number between 0 and the true value of the common fund. This number 
corresponds to the reported value of the common fund. The reported value of the common fund will be split equally between the co-participants. That is, each co-participant (including the appointed co-participant) will receive $1 / 3$ of the reported value of the common fund. If applicable, the appointed co-participant will also earn the whole of the non-reported value of the common fund, that is the value of the common fund not reported. Note that the appointed co-participant will be free to report or not the true value of the common fund. Moreover, the other co-participants will only be informed of the reported value of the common fund.

Example: Suppose the appointed co-participant solves 52 tables correctly (hence 12 tables over and above 40 correctly solved tables); the value of the common fund is $12 \times 4=48$. The appointed co-participant however reports a value of 33 . The non-reported value of the common fund is $48-33=15$. The earnings are therefore:

- 33 / 3 = 11 for each non-appointed co-participant;

- $33 / 3+15=26$ for the appointed co-participant.

How is the appointed co-participant selected? Before starting the task, each co-participant will be placed in 7 situations. Only one of these will be real, the others will be fictional.

In each situation, each co-participant will be informed of:

- the number of tables correctly solved by each other co-participant in the first stage of the experiment where the task was to count $1 \mathrm{~s}$ in tables;

- the proportion of points that each other co-participant in the role of participant B returned to participant $\mathrm{A}$ in the second stage of the experiment.

However, only in the real situation, the information provided is about your actual current coparticipants. In the fictional situations, the information provided is about people who participated in past sessions of this experiment.

For each situation, each co-participant will be asked to choose which of the two other coparticipants he or she would like to select as the appointed co-participant. Only the decision of one randomly selected co-participant in the real situation will be implemented and count towards your earnings of this stage. Note that, for all you know, each situation could be the real one, in which case ALL information you are given about it is true, and only the real one may have any effect on who is going to be the appointed co-participant. Hence, it is in your best interest to treat each situation as if it is real and to choose, for each situation, the coparticipant that you really want as the appointed co-participant.

Afterwards, the computer will inform each co-participant whether or not he or she is the appointed co-participant based on the outcome of the real situation. Then the task of counting $1 \mathrm{~s}$ in a series of tables will start.

\section{In summary}

- You will be randomly matched with two other participants you have never been matched with before. You and these two participants will be referred to as co- 
participants. The three of you will have a common fund with an initial value of 0 points.

- Each co-participant will choose whom he or she wants to select as appointed coparticipant between the other two co-participants in different situations. Only one of these situations is the real one. The decision of one co-participant selected at random in the real situation will be implemented.

- Everyone will work for 10 minutes on the task which consists in counting $1 \mathrm{~s}$ in a series of tables containing 0s and 1s. However, only the work of the appointed coparticipant will count for the earnings. Specifically, for each table that the appointed co-participant correctly solves on top of the first 40 correctly solved tables, the value of the common fund increases by 4 points.

- At the end of the task the appointed co-participant can report any number between 0 and the true value of the common fund to the other co-participants. This number constitutes the reported value of the common fund. The other co-participants will be informed only about the reported value of the common fund.

- The reported value of the common fund will be divided in equal parts (each worth $1 / 3$ of the reported value) between the co-participants (including the appointed coparticipant). If applicable, the appointed co-participant will also earn the whole of the non-reported value of the common fund, that is the value of common fund not reported.

\section{B. Final questionnaire}

Note: In the Part 1 of the questionnaire, appointed and non-appointed co-participants were asked different questions (see below).

\section{Part 1 (only for non-appointed co-participants)}

In this part of the questionnaire, we would like you to answer the following questions regarding your predictions about stage 3 . You will be paid an extra point for each correct prediction.

1) Do you think the appointed co-participant underreported the value of the common fund?

Yes or No

2) Do you think the other co-participant who was not selected as the appointed coparticipant voted for the same co-participant as you?

Yes or No

3) How do you feel the appointed co-participant was ranked among the three coparticipants in terms of number of tables correctly solved in stage 1 ?

He/she was ranked first (i.e. he/she correctly solved the largest number of tables)

He/she was ranked second 
He/she was ranked third (i.e. he/she correctly solved the smallest number of tables)

4) How do you feel the appointed co-participant was ranked among the three coparticipants in terms of number of points returned to participant $\mathrm{A}$ in stage 2

He/she was ranked first (i.e. he/she returned the largest number of points)

He/she was ranked second

He/she was ranked third (i.e. he/she returned the smallest number of points)

Part 1 (only for appointed co-participants)

1) Do you think both the other two co-participants voted for you as the appointed coparticipant?

Yes or No

2) Do you think that the co-participant, selected at random, who voted for you thought that you were going to underreport the value of the common fund?

Yes or No

3) How do you feel you were ranked among the three co-participants in terms of number of tables correctly solved in stage 1 ?

I was ranked first (i.e. I correctly solved the largest number of tables)

I was ranked second

I was ranked third (i.e. I correctly solved the smallest number of tables)

4) How do you feel you were ranked among the three co-participants in terms of number of points returned to participant $\mathrm{A}$ in stage 2 ?

I was ranked first (i.e. I returned the largest number of points)

I was ranked second

I was ranked third (i.e. I returned the smallest number of points)

\section{Part 2}

You will now be asked to select from among six different gambles the one gamble you would like to take. The figure shows the kind of screen you will use to select the gamble. 


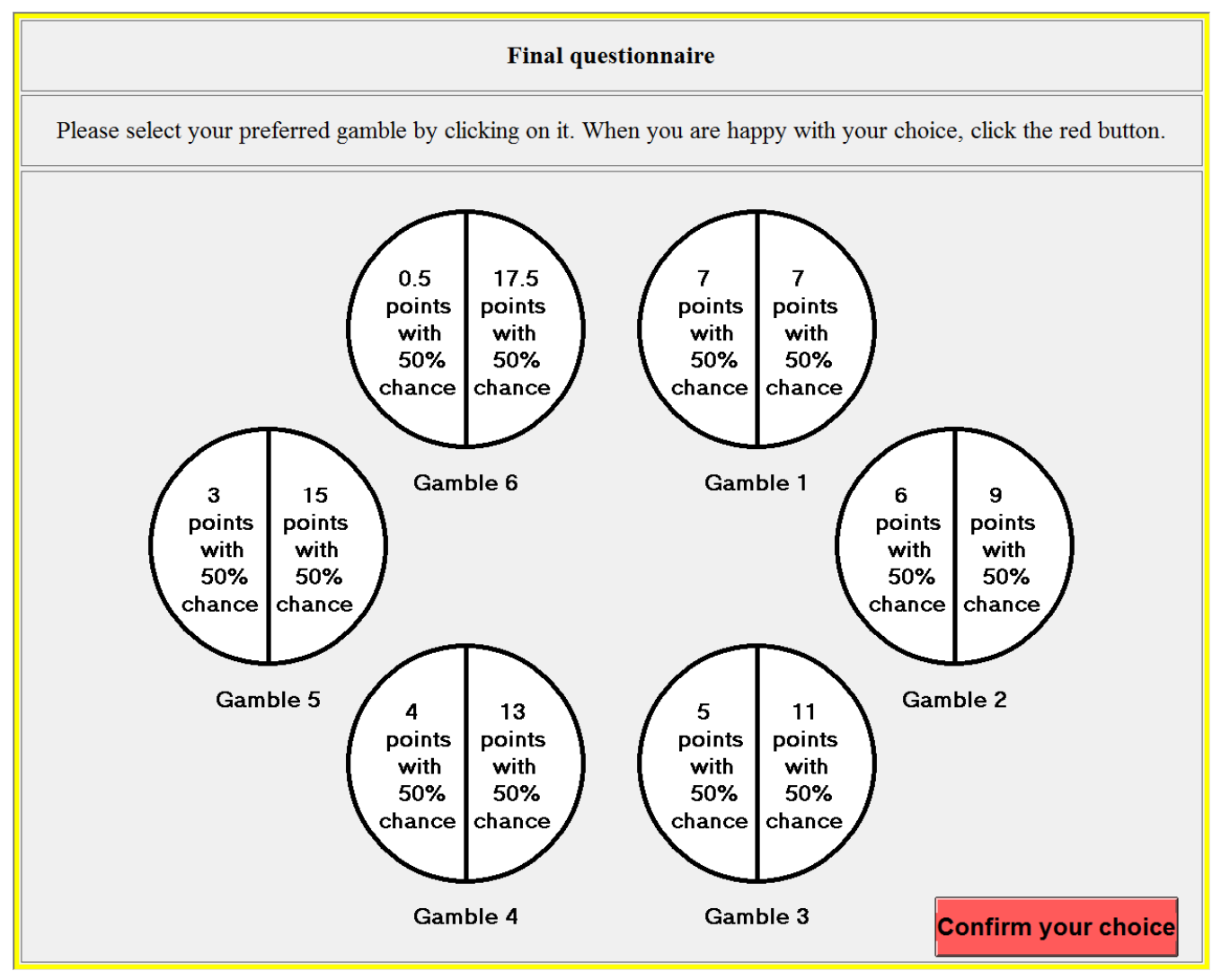

Each circle represents a different gamble. Each circle is divided in two parts. Each part is a possible outcome of the gamble. For every gamble, each outcome is equally likely, that is it has a $50 \%$ chance of happening. The number of points that the gamble will give for each possible outcome is written inside the circle.

At the end of the experiment, you will roll a six-sided die to determine which outcome of your selected gamble will occur:

- If you roll a 1, 2, or 3, you will receive the points on the left part of the circle.

- If you roll a 4, 5, or 6, you will receive the points on the right side of the circle.

Note that, no matter which gamble you pick, each outcome has a $50 \%$ chance of occurring.

To select a gamble you have to click on it with the mouse. You can revise your choice as many times as you want. When you are happy with your choice, click the "Confirm your choice" button to confirm.

Example: Suppose you select gamble 4 and later you roll a 1, 2, or 3, your earnings will be 4 points. If you roll 4, 5, or 6 , you will earn 13 points.

\section{Part 3}


A list of statements will be displayed. Please read each statement carefully and decide if that statement describes you or not. If it describes you click the word true if not, choose the word false. After each response a new statement will appear. There are sixteen statements.

1. I sometimes litter.

2. I always admit my mistakes openly and face the potential negative consequences.

3. In traffic I am always polite and considerate of others.

4. I have tried illegal drugs (for example, marijuana, cocaine, etc.).

5. I always accept others' opinions, even when they don't agree with my own.

6. I take out my bad moods on others now and then.

7. There has been an occasion when I took advantage of someone else.

8. In conversations I always listen attentively and let others finish their sentences.

9. I never hesitate to help someone in case of emergency.

10. When I have made a promise, I keep it--no ifs, ands or buts.

11. I occasionally speak badly of others behind their back.

12. I would never live off other people.

13. I always stay friendly and courteous with other people, even when I am stressed out.

14. During arguments I always stay objective and matter-of-fact.

15. There has been at least one occasion when I failed to return an item that I borrowed.

16. I always eat a healthy diet.

17. Sometimes I only help because I expect something in return

For each statement, subjects were asked to select True or False.

\section{Part 4}

A list of attitude statements will be displayed. Each represents a commonly held opinion and there are no right or wrong answers. Read each statement carefully. Then indicate the extent to which you agree or disagree. First impressions are usually best in such matters. After each response a new statement will appear. There are twenty statements.

1. Never tell anyone the real reason you did something unless it is useful to do so.

2. The best way to handle people is to tell them what they want to hear. 
3. One should take action only when sure it is morally right.

4. Most people are basically good and kind.

5. It is safest to assume that all people have a vicious streak and it will come out when they are given a chance.

6. Honesty is the best policy in all cases.

7. There is no excuse for lying to someone else.

8. Generally speaking, men won't work hard unless they're forced to do so.

9. All in all, it is better to be humble and honest than important and dishonest.

10. When you ask someone to do something for you, it is best to give the real reasons for wanting it rather than giving reasons that carry more weight.

11. Most people who get ahead in the world lead clean, moral lives.

12. Anyone who completely trusts anyone else is asking for trouble.

13. The biggest difference between most criminals and other people is that criminals are stupid enough to get caught.

14. Most men are brave.

15. It is wise to flatter important people.

16. It is possible to be good in all respects.

17. Barnum was very wrong when he said that there's a sucker born every minute.

18. It is hard to get ahead without cutting corners here and there.

19. People suffering from incurable diseases should have the choice of being put painlessly to death.

20. Most men forget more easily the death of their father than the loss of their property.

For each statement, subjects were asked to select one of the following options: strongly disagree, somewhat disagree, slightly disagree, no opinion, slightly agree, somewhat agree, strongly agree.

\section{Part 5}

In this part of the questionnaire, we would like you to provide some personal information if so you wish.

What is your gender? (Female or Male) 
What is your country of origin?

Are you a native English speaker? (Yes or No)

Your age?

Which course are you registered on?

Did you attend a course in Economics during your studies? (Yes or No)

Level of current degree? (INTO, Undergraduate (e.g.BSc, BA, LLB, MBBS), Postgraduate Taught (e.g.MA, MSc), Postgraduate Research (e.g. MPhil, PhD) or Other)

*If you ticked the "Other" in the question above please specify if you wish

What is your religion or belief? (No Religion, Buddhist, Christian, Sikh, Muslim, Confucian, Hindu, Jewish, Atheist, Other or Prefer not to say)

*If you ticked the "Other" in the question above please specify if you wish

What is your relationship status? (Single, Engaged, In a relationship, Married, Civil Partnership, Widowed, Seperated/ Divorced or Prefer not to say)

How many times have you participated in previous experiments? $(0,1,2,3$ or More than 3$)$

Have you ever participated before in an experiment where the task was to count $1 \mathrm{~s}$ in a series of table containing 0s and 1s like in this experiment? (Yes or No)

What do you think this experiment is about? 


\section{Background information on participants}

\begin{tabular}{cc}
\hline \hline Characteristics & $\mathbf{n = 2 4 0}$ \\
\hline Gender & \\
Female & $150(62.50 \%)$ \\
Male & $90(37.50 \%)$ \\
\hline Age & \\
Mean & 23.30 \\
St. dev. & 4.43 \\
Min. & 18 \\
Max. & 65 \\
\hline Level of current degree & $3(1.25 \%)$ \\
INTO & $1(0.42 \%)$ \\
Erasmus & $19(7.92 \%)$ \\
Postgraduate Research (e.g. MPhil, PhD) & $95(39.58 \%)$ \\
Postgraduate Taught (e.g.MA, MSc) & $122(50.83 \%)$ \\
Undergraduate (e.g.BSc, BA, LLB, MBBS) & \\
\hline Background in economics ${ }^{I}$ & $130(54.17 \%)$ \\
No & $110(45.83 \%)$ \\
Yes
\end{tabular}

\section{Country of origin}

Bahrain

$1(0.42 \%)$

Bangladesh

$1(0.42 \%)$

Brazil

$1(0.42 \%)$

Bulgaria

China, Taiwan or Hong Kong

$1(0.42 \%)$

$98(40.83 \%)$

$\begin{array}{cc}\text { Egypt } & 1(0.42 \%) \\ \text { Germany } & 4(1.67 \%) \\ \text { Greece } & 2(0.83 \%) \\ \text { Hungary } & 1(0.42 \%) \\ \text { India } & 2(0.83 \%) \\ \text { Indonesia } & 1(0.42 \%) \\ \text { Iran } & 2(0.83 \%) \\ \text { Ireland } & 2(0.83 \%) \\ \text { Italy } & 1(0.42 \%) \\ \text { Japan } & 1(0.42 \%) \\ \text { Jordan } & 1(0.42 \%) \\ \text { Kazakhstan } & 2(0.83 \%) \\ \text { Latvia } & 1(0.42 \%) \\ \text { Lithuania } & 3(1.25 \%) \\ \text { Malaysia } & 4(1.67 \%) \\ \text { Maldives } & 1(0.42 \%) \\ \text { Mauritius } & 4(1.67 \%) \\ \text { Netherlands } & 1(0.42 \%) \\ \text { Nigeria } & 4(1.67 \%) \\ \text { Norway } & 1(0.42 \%) \\ \text { Palestine } & 1(0.42 \%)\end{array}$

${ }^{1}$ The question was: "Did you attend a course in Economics during your studies?" Yes or No. 


\begin{tabular}{|c|c|}
\hline Philippines & $1(0.42 \%)$ \\
\hline Poland & $5(2.08 \%)$ \\
\hline Portugal & $1(0.42 \%)$ \\
\hline Romania & $1(0.42 \%)$ \\
\hline Russia & $2(0.83 \%)$ \\
\hline Somalia & $1(0.42 \%)$ \\
\hline Sri Lanka & $1(0.42 \%)$ \\
\hline Tanzania & $1(0.42 \%)$ \\
\hline Thailand & $2(0.83 \%)$ \\
\hline UK & $67(27.92 \%)$ \\
\hline USA & $4(1.67 \%)$ \\
\hline Vietnam & $12(5 \%)$ \\
\hline \multicolumn{2}{|l|}{ Native English speaker } \\
\hline No & $160(66.67 \%)$ \\
\hline Yes & $80(33.33 \%)$ \\
\hline \multicolumn{2}{|l|}{ Relationship Status } \\
\hline Engaged & $3(1.25 \%)$ \\
\hline In a relationship & $81(33.75 \%)$ \\
\hline Married & $9(3.75 \%)$ \\
\hline Prefer not to say & $7(2.92 \%)$ \\
\hline Separated/ Divorced & $1(0.42 \%)$ \\
\hline Single & $139(57.92 \%)$ \\
\hline \multicolumn{2}{|l|}{ Religion or belief } \\
\hline Atheist & $20(8.33 \%)$ \\
\hline Agnostic & $1(0.42 \%)$ \\
\hline Buddhist & $16(6.67 \%)$ \\
\hline Christian & $43(17.92 \%)$ \\
\hline Christian and Sikh & $1(0.42 \%)$ \\
\hline Daoism & $1(0.42 \%)$ \\
\hline Muslim & $18(7.5 \%)$ \\
\hline No Religion & $123(51.25 \%)$ \\
\hline Other & $4(1.67 \%)$ \\
\hline Prefer not to say & $13(5.42 \%)$ \\
\hline \multicolumn{2}{|c|}{ Participation in previous experiments (n.) } \\
\hline Never & $8(3.33 \%)$ \\
\hline 1 & $25(10.42 \%)$ \\
\hline 2 & $16(6.67 \%)$ \\
\hline 3 & $15(6.25 \%)$ \\
\hline 4 or more & $176(73.33 \%)$ \\
\hline \multicolumn{2}{|c|}{ Participation in a similar real-effort task } \\
\hline No & $146(60.83 \%)$ \\
\hline Yes & $94(39.17 \%)$ \\
\hline
\end{tabular}




\section{Full regressions of Table 4}

Table D1: Conditional Logit Regressions

\begin{tabular}{|c|c|c|c|c|}
\hline & \multicolumn{2}{|c|}{ Regression 3} & \multicolumn{2}{|c|}{ Regression 6} \\
\hline & $\mathrm{b}$ & se & $\mathrm{b}$ & se \\
\hline $\log$ (Trustworthiness) & $4.38 * * *$ & 1.31 & $5.20 * * *$ & 1.59 \\
\hline $\log ($ Competence $)$ & $2.76^{* *}$ & 1.2 & $2.98 * *$ & 1.21 \\
\hline $\log ($ Trustworthiness) $\times$ Inconsistency & & & $-2.89 * * *$ & 0.56 \\
\hline $\log ($ Competence $) \times$ Inconsistency & & & $-1.49 * *$ & 0.68 \\
\hline $\log ($ Trustworthiness $) \times|\mathrm{p}|>5$ & $-2.49 * *$ & 1.08 & $-2.37 * *$ & 1.18 \\
\hline $\log ($ Competence $) \times|p|>5$ & $-1.61 * *$ & 0.81 & $-1.46^{*}$ & 0.86 \\
\hline $\log ($ Trustworthiness $) \times U K$ & 1.86 & 1.66 & 1.45 & 1.65 \\
\hline $\log ($ Competence $) \times U K$ & 2.1 & 2.13 & 1.65 & 2.1 \\
\hline $\log ($ Trustworthiness $) \times$ China & -0.06 & 0.62 & -0.35 & 0.69 \\
\hline $\log ($ Competence $) \times$ China & 0.14 & 0.66 & -0.13 & 0.65 \\
\hline $\log$ (Trustworthiness) $\times$ Male & -0.19 & 0.65 & -0.61 & 0.84 \\
\hline $\log ($ Competence $) \times$ Male & 0.99 & 0.63 & 0.88 & 0.8 \\
\hline $\log ($ Trustworthiness $) \times$ Economics & -0.14 & 0.56 & 0.24 & 0.57 \\
\hline $\log ($ Competence $) \times$ Economics & -0.17 & 0.5 & 0.2 & 0.54 \\
\hline $\log ($ Trustworthiness $) \times$ Age & 0.02 & 0.15 & -0.02 & 0.14 \\
\hline $\log ($ Competence $) \times$ Age & 0.05 & 0.17 & 0.02 & 0.16 \\
\hline $\log$ (Trustworthiness) $\times$ Undergraduate & 0.1 & 0.71 & -0.17 & 0.72 \\
\hline $\log ($ Competence $) \times$ Undergraduate & 0.03 & 0.92 & -0.2 & 0.89 \\
\hline $\log ($ Trustworthiness $) \times$ Trust Game first & -0.45 & 0.57 & -0.23 & 0.58 \\
\hline $\log ($ Competence $) \times$ Trust Game first & -0.37 & 0.58 & -0.01 & 0.6 \\
\hline $\log ($ Trustworthiness $) \times \mathrm{CIL}$ & 0.4 & 0.5 & $0.96^{*}$ & 0.53 \\
\hline $\log ($ Competence $) \times C I L$ & 0.46 & 0.61 & 1 & 0.66 \\
\hline $\log ($ Trustworthiness $) \times$ Risk choice & -0.12 & 0.17 & -0.31 & 0.21 \\
\hline $\log ($ Competence $) \times$ Risk choice & -0.02 & 0.18 & -0.15 & 0.21 \\
\hline $\log ($ Trustworthiness $) \times$ SDS17 Score & 0.02 & 0.09 & 0.08 & 0.07 \\
\hline $\log ($ Competence $) \times$ SDS17 Score & 0.01 & 0.09 & 0.07 & 0.09 \\
\hline $\log$ (Trustworthiness) $\times$ MACH Score & -0.02 & 0.02 & 0.01 & 0.03 \\
\hline $\log ($ Competence $) \times$ MACH Score & 0.01 & 0.02 & 0.03 & 0.03 \\
\hline $\log ($ Trustworthiness $) \times$ Voter's Return rate & -0.14 & 0.41 & 0.13 & 0.39 \\
\hline $\log ($ Competence $) \times$ Voter's Return rate & 0 & 0.51 & 0.17 & 0.55 \\
\hline $\log ($ Trustworthiness $) \times$ Voter's Competence & -0.31 & 0.36 & 0.13 & 0.42 \\
\hline $\log ($ Competence $) \times$ Voter's Competence & 0.26 & 0.41 & 0.59 & 0.44 \\
\hline Obs & 776 & & 776 & \\
\hline Pseudo $\mathrm{R}^{2}$ & 0.31 & & 0.38 & \\
\hline Df & 30 & & 32 & \\
\hline Prob $>F$ & 0 & & 0 & \\
\hline
\end{tabular}




\section{E. Analysis with rational expectations}

In this section, we replicate the analysis of the paper assuming that subjects have rational expectations. If subjects display rational expectations, they are on average able to predict the candidate that ex post will generate more profit. We can construct a measure of the expected ex post payoffs generated to the voters by the candidates by looking at how much ex ante trustworthiness and ex ante competence of the public officials explain the ex post payoffs generated to the voters by the public officials. In particular, we can estimate an OLS regression where the dependent variable is the ex post voter's payoffs generated by the public officials, ${ }^{2}$ while the independent variables are the ex ante trustworthiness (measured as the return rate from the earlier stage) and ex ante competence (measured as number of tables correctly solved on top of the first 40 tables correctly solved in the earlier stage) of the public officials. We can then multiply the estimated coefficients with the ex ante trustworthiness and the ex ante competence respectively of all the candidates (both appointed and non-appointed participants) to obtain a statistical expected measure of the expected ex post payoffs generated to the voters by the candidates. Table E1 presents the result of this estimation.

Table E1: OLS regression on ex post voter's payoffs

\begin{tabular}{ccc}
\hline \hline & \multicolumn{2}{c}{ Ex-post voter's payoffs } \\
\cline { 2 - 3 } & $\mathrm{b}$ & $\mathrm{se}$ \\
\hline Ex-ante Trustworthiness & $34.24 * *$ & 14.86 \\
Ex-ante Competence & $0.74 * * *$ & 0.12 \\
\hline Obs & 80 & \\
Adj. $\mathrm{R}^{2}$ & 0.317 & \\
Df & 2 & \\
Prob > F & 0 & \\
\hline Notes: OLS regression.
\end{tabular}

and the standard errors. Observations are from the public officials. $* \mathrm{p}<0.1, * * \mathrm{p}<0.05, * * * \mathrm{p}<0.01$. The coefficients are not normalized.

The expected values of the ex post profits are calculated using the following formula:

$$
\pi_{i, k}^{\text {ex post }}=34.24 \times T_{j, k}^{e x \text { ante }}+0.74 \times A_{j, k}^{e x \text { ante }}
$$

where $T_{j, k}^{e x}$ ante and $A_{j, k}^{e x}$ ante are the ex ante trustworthiness and ex ante competence respectively of the candidate $j$. Having now a measure of the ex post voter's payoffs

\footnotetext{
${ }^{2}$ These payoffs are calculated as: $\pi_{i, k}^{\text {ex post }}=\frac{4}{3} T_{p, k}^{\text {ex post }} A_{p, k}^{\text {ex post }}$, where $i$ identifies the voter, $k$ the triad, $T_{p, k}^{\text {ex post }}$

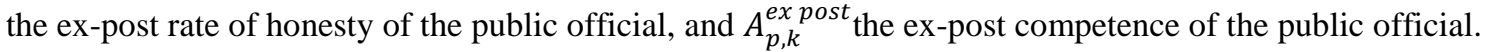


generated by the candidates, we can study whether subjects displayed rational expectations. In particular, we can look at how the probability of voting for the more (ex post) profitable candidate evolves as the difference in ex post payoffs between the more and less profitable candidates increases (Figure E1). ${ }^{3}$ If subjects have rational expectations, they should always select the more (ex post) profitable candidate (graphically, we should observe a straight line at $\mathrm{P}(\max (\pi))=1)$. This seems to be the tendency when the difference in ex post payoffs between the more and less profitable candidates is large. When the difference is small, decisions are noisier.

Figure E1: Probability of electing the ex post more profitable candidate

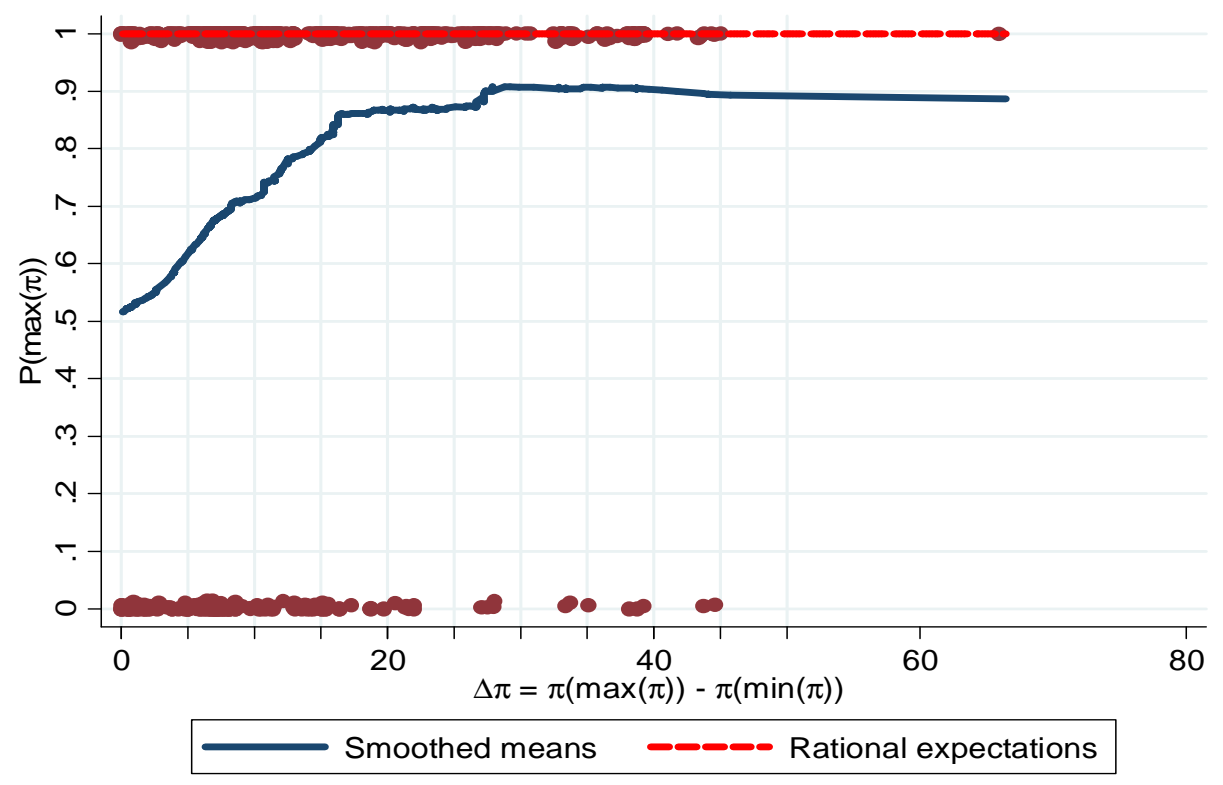

Notes: $\mathrm{P}(\max (\pi))$ is the probability of electing the ex post more profitable candidate. $\Delta \pi$ is the difference in expected payoffs between the more and less ex post profitable candidate. The running means are weighted to give more importance to near points than far, and computed using a bandwith of 0.6 (60\% of the data).

We can also study whether the voters favor the ex post trustworthy or competent candidate. To do so, we need to obtain a measure of ex post trustworthiness and ex post competence for all the candidates. We can estimate two OLS regressions, one for trustworthiness and one for competence, where the dependent variable is the ex post trustworthiness (competence) of the public officials, while the independent variable is the ex ante trustworthiness (competence) of the public officials. We can then multiply the estimated coefficients with the ex ante trustworthiness and the ex ante competence respectively of all the candidates (both appointed and non-appointed participants) to obtain a statistical expected

\footnotetext{
${ }^{3}$ The probability is obtained by computing the weighted running means of a dichotomous variable taking value 1 when the ex-post more profitable candidate is elected and 0 otherwise.
} 
measure of the ex post trustworthiness and ex post competence respectively. Table E2 presents the result of these estimations.

Table E2: OLS regressions on ex post trustworthiness and competence

\begin{tabular}{ccccc}
\hline \hline & \multicolumn{2}{c}{ Ex-post trustworthiness } & \multicolumn{2}{c}{ Ex-post competence } \\
\cline { 2 - 5 } & $\mathrm{b}$ & $\mathrm{se}$ & $\mathrm{b}$ & $\mathrm{se}$ \\
\hline Ex-ante Trustworthiness & $0.50^{* *}$ & 0.19 & $\cdot$ & $\cdot$ \\
Ex-ante Competence &. &. & $0.89^{* * *}$ & 0.05 \\
\hline Obs & 80 & & 80 & \\
Adj. $\mathrm{R}^{2}$ & 0.069 & & 0.795 & \\
Df & 1 & & 1 & \\
Prob $>\mathrm{F}$ & 0.010 & & 0 & \\
\hline
\end{tabular}

Notes: OLS regression. The table reports the beta coefficients and the standard errors. Observations are from the public officials. $* p<0.1, * * p<0.05, * * * p<0.01$. The coefficients are not normalized.

Focusing on cases where there is a trade-off between ex post trustworthiness and ex post competence, we can look at how the probability of voting for the more ex post trustworthy candidate evolves if the difference in ex post payoffs $\Delta \pi$ between the more and less trustworthy candidates increases (Figure E2). For $\Delta \pi<0$ (i.e. the ex post more trustworthy candidate is also the ex post less profitable), profit-maximizing subjects with rational expectations should vote for the ex post less trustworthy subjects as he or she is associated with higher ex post payoffs. For $\Delta \pi>0$ (i.e. the ex post more trustworthy candidate is also the ex post more profitable), profit-maximizing subjects with rational expectations should vote for the ex post more trustworthy subjects as he or she is associated with higher ex post payoffs. The figure shows that subjects did not seem to vote for the ex post more profitable candidate, as rational expectations would predict, but the candidate who is ex post more trustworthy, especially when the difference in ex post payoffs between the candidates is small. This pattern is similar to the one observed for adaptive expectations (see main paper), and, perhaps, even more marked. 
Figure E2: Probability of electing the ex post more trustworthy candidate

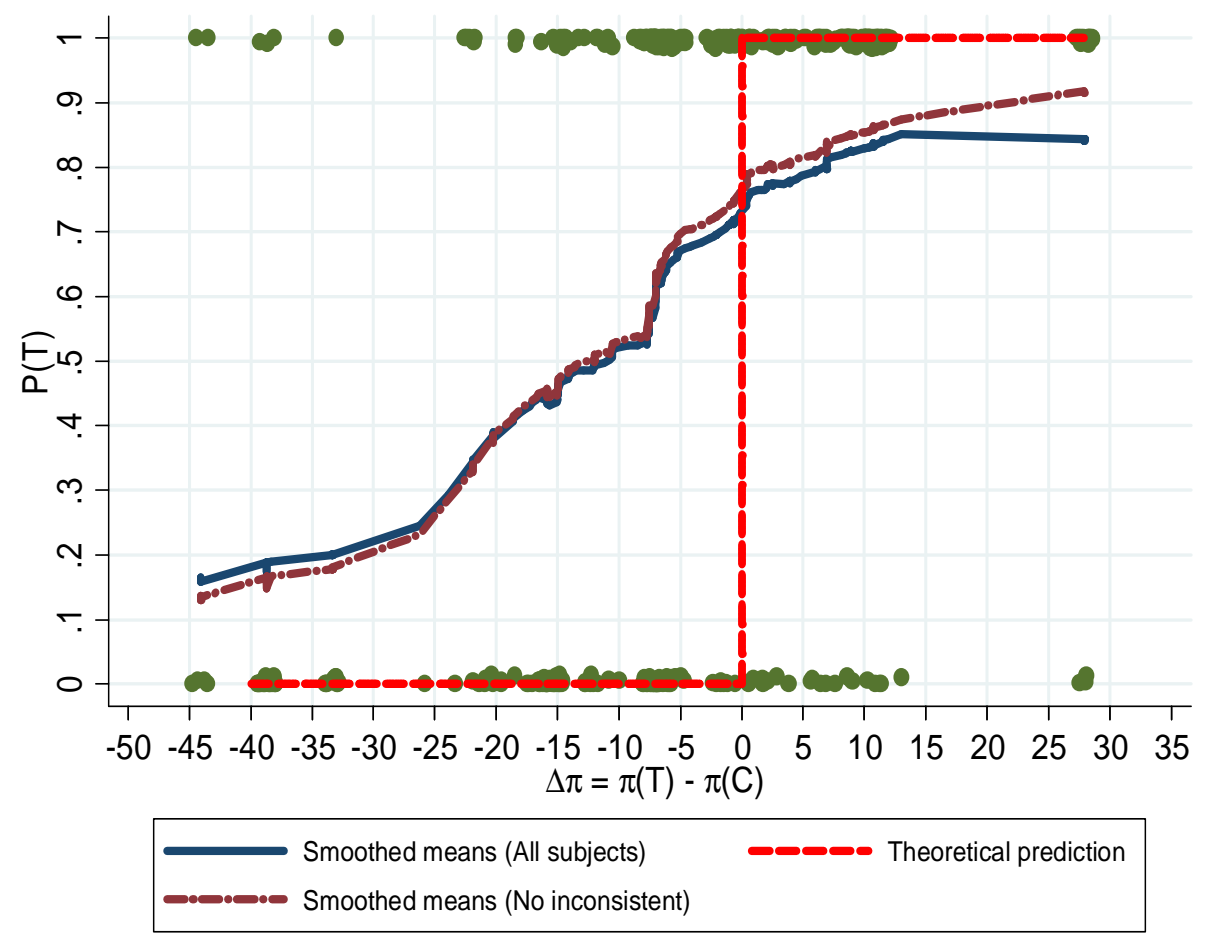

Notes: $\mathrm{P}(\mathrm{T})$ is the probability of electing the more ex post trustworthy candidate. $\Delta \pi$ is the difference in expected payoffs between the more and less ex post trustworthy candidate. The running means are weighted to give more importance to near points than far, and computed using a bandwith of $0.6(60 \%$ of the data). The data corresponds to cases where there is a trade-off between ex post trustworthiness and competence.

We can also conduct a regression analysis like the one in the paper but using the ex post measures of trustworthiness and competence. The dependent variable is the dummy 'Vote'. In regression 1, the independent variables include the log of ex post trustworthiness and ex post competence of the candidate. In regression 2, we also add interaction terms of $\log ($ ex post trustworthiness $)$ and $\log ($ ex post competence $)$ with a dummy variable $|\pi|>5$ which takes value 1 when the absolute deviation in ex post expected payoffs between the two candidates is bigger than 5 experimental points. In regression 3, we control as well for the demographic, psychological and behavioral characteristics of the voters and treatment effects by interacting them with $\log ($ ex post trustworthiness $)$ and $\log ($ ex post competence $){ }^{4}$ In regressions 4-6, we also control for the behavior of the inconsistent subjects by including an interaction of whether a subject was categorized as inconsistent with $\log (\mathrm{ex}$ post

\footnotetext{
${ }^{4}$ As we already explained in the paper, since the characteristics of the voters do not vary over the choices of the voters, in the regression we can only have interaction terms between the alternative-specific variables and the voter-specific variables.
} 
trustworthiness) and $\log ($ ex post competence) respectively. Table E3 displays the results of the regressions. ${ }^{5}$

Table E3: Alternative-specific conditional logit regressions

\begin{tabular}{|c|c|c|c|c|c|c|}
\hline & \multicolumn{2}{|c|}{ Regression 1} & \multicolumn{2}{|c|}{ Regression 2} & \multicolumn{2}{|c|}{ Regression 3} \\
\hline & $\mathrm{b}$ & se & $\mathrm{b}$ & se & $\mathrm{b}$ & se \\
\hline $\log$ (Trustworthiness) & $1.37 * * *$ & 0.24 & $1.56 * * *$ & 0.47 & $1.78 * *$ & 0.81 \\
\hline $\log ($ Competence $)$ & $0.98 * * *$ & 0.22 & $0.49^{*}$ & 0.27 & -0.47 & 0.92 \\
\hline $\log ($ Trustworthiness $) \times|\pi|>5$ & & & -0.24 & 0.47 & -0.17 & 0.53 \\
\hline $\log ($ Competence $) \times|\pi|>5$ & & & 0.52 & 0.36 & 0.9 & 0.61 \\
\hline $\begin{array}{l}\text { Interactions with demographic, } \\
\text { behavioral, psychological and } \\
\text { treatment variables }\end{array}$ & \multicolumn{2}{|l|}{ No } & \multicolumn{2}{|c|}{ No } & \multicolumn{2}{|c|}{ Yes } \\
\hline Obs & 774 & & 774 & & 772 & \\
\hline Pseudo $\mathrm{R}^{2}$ & 0.23 & & 0.24 & & 0.3 & \\
\hline Df & 2 & & 4 & & 30 & \\
\hline \multirow[t]{3}{*}{ Prob $>F$} & 0 & & 0 & & 0 & \\
\hline & \multicolumn{2}{|c|}{ Regression 4} & \multicolumn{2}{|c|}{ Regression 5} & \multicolumn{2}{|c|}{ Regression 6} \\
\hline & $\mathrm{b}$ & se & $\mathrm{b}$ & se & $\mathrm{b}$ & se \\
\hline $\log$ (Trustworthiness) & $1.75 * * *$ & 0.28 & $1.81 * * *$ & 0.47 & $2.40 * * *$ & 0.92 \\
\hline $\log ($ Competence $)$ & $1.16^{* * *}$ & 0.26 & $0.52 *$ & 0.28 & -0.59 & 0.96 \\
\hline $\log$ (Trustworthiness) $\times$ Inconsistency & $-1.78 * * *$ & 0.45 & $-1.78 * * *$ & 0.46 & $-2.84 * * *$ & 0.58 \\
\hline $\log ($ Competence $) \times$ Inconsistency & -0.63 & 0.5 & -0.64 & 0.53 & $-1.12 * *$ & 0.52 \\
\hline $\log ($ Trustworthiness $) \times|\pi|>5$ & & & -0.11 & 0.5 & 0.12 & 0.57 \\
\hline $\log ($ Competence $) \times|\pi|>5$ & & & $0.69^{*}$ & 0.39 & $1.25^{*}$ & 0.7 \\
\hline $\begin{array}{c}\text { Interactions with demographic, } \\
\text { behavioral, psychological and } \\
\text { treatment variables }\end{array}$ & \multicolumn{2}{|c|}{ No } & \multicolumn{2}{|c|}{ No } & \multicolumn{2}{|c|}{ Yes } \\
\hline Obs & 774 & & 774 & & 772 & \\
\hline Pseudo $\mathrm{R}^{2}$ & 0.28 & & 0.29 & & 0.37 & \\
\hline Df & 4 & & 6 & & 32 & \\
\hline Prob $>F$ & 0 & & 0 & & 0 & \\
\hline
\end{tabular}

Notes: Alternative-specific logit regression with clustered robust standard errors. The table reports the beta coefficients and the standard errors. The demographic variables are age, gender ( $=1$ for men), economics background (= 1 if applicable), nationality (UK $=1$ for UK subjects, and China $=1$ for Chinese subjects), and University status (= 1 for undergraduate students). The behavioral variables are the competence and trustworthiness of the voter. The psychological variables are the risk attitude, the SDS17 score and MACH score. The treatment variables are the CIL sessions, and the sessions where the trust game stage took place before the real effort task stage. The psychological and behavioral variables and age are centered at the mean in order to control for high correlation between the independent variables (see Marquardt, 1980). 'China' identifies subjects from China, Taiwan or Hong Kong. The data correspond to cases where there was a trade-off between trustworthiness and competence. The full regressions are available from the authors upon request. $* p<0.1, * *$ $p<0.05, * * * x<0.01$.

In Regressions 1 and 4 , both the coefficients of $\log$ (trustworthiness) and $\log ($ competence) are positive and strongly significantly. The coefficient of $\log$ (trustworthiness) is also significantly larger than the coefficient of $\log$ (competence) $\left(\chi^{2}\right.$ test, $p=0.056$ in Regression 1, and 0.010 in Regression 4). This indicates that, if we assume

\footnotetext{
${ }^{5}$ The full regressions are available upon request.
} 
that voters have rational expectations, the bias towards caring about trustworthiness carries through and is perhaps even stronger. If we focus on small differences in ex post expected payoffs between the two candidates (Regressions 2-3 and 5-6), the coefficient for $\log$ (trustworthiness) becomes even larger than the coefficient for $\log$ (competence). Alltogher these results support the key finding of the paper that people care about the trustworthiness of the candidates.

Finally, we can compare how many electoral choices were consistent with rational expectations and how many electoral choices were consistent with adaptive expectations. This information is summarized in Tables E4 and E5. Both tables show that a significant proportion of choices were consistent with either adaptive or rational expectations. In addition, they suggest that more choices display adaptive $(84.38 \%$ for all the subjects, $88.08 \%$ if we exclude the inconsistent subjects) rather than rational $(75.30 \%$ for all the subjects, $78.31 \%$ if we exclude the inconsistent subjects) expectations ( $\chi^{2}$ test, $p<0.001$ ).

Table E4: Electoral choices consistent with adaptive or rational expectations

\begin{tabular}{c|ccc|ccc}
\hline \hline & \multicolumn{3}{|c|}{ All subjects } & \multicolumn{3}{c}{ No inconsistent subjects } \\
\hline $\begin{array}{c}\text { Adaptive } \\
\text { expectations }\end{array}$ & Baseline & CIL & Total & Baseline & CIL & Total \\
\hline NO & 31 & 74 & 105 & 26 & 46 & 72 \\
& $(18.45 \%)$ & $(14.68 \%)$ & $(15.63 \%)$ & $(15.95 \%)$ & $(10.43 \%)$ & $(11.92 \%)$ \\
YES & 137 & 430 & 567 & 137 & 395 & 532 \\
Total & $(81.55 \%)$ & $(85.32 \%)$ & $(84.38 \%)$ & $(84.05 \%)$ & $(89.57 \%)$ & $(88.08 \%)$ \\
Rational & $168(100 \%)$ & $504(100 \%)$ & $672(100 \%)$ & $163(100 \%)$ & $441(100 \%)$ & $604(100 \%)$ \\
expectations & Baseline & CIL & Total & Baseline & CIL & Total \\
\hline NO & 44 & 122 & 166 & 39 & 92 & 131 \\
& $(26.19 \%)$ & $(24.21 \%)$ & $(24.7 \%)$ & $(23.93 \%)$ & $(20.86 \%)$ & $(21.69 \%)$ \\
YES & 124 & 382 & 506 & 124 & 349 & 473 \\
Total & $(73.81 \%)$ & $(75.79 \%)$ & $(75.3 \%)$ & $(76.07 \%)$ & $(79.14 \%)$ & $(78.31 \%)$ \\
& $168(100 \%)$ & $504(100 \%)$ & $672(100 \%)$ & $163(100 \%)$ & $441(100 \%)$ & $604(100 \%)$ \\
\hline
\end{tabular}


Table E5: Electoral choices consistent with adaptive and/or rational expectations

\begin{tabular}{cccc}
\hline \hline Baseline & \multicolumn{4}{c}{ Rational expectations } \\
\hline Adaptive expectations & NO & YES & Total \\
NO & $23(4.56 \%)$ & $8(1.59 \%)$ & $31(6.15 \%)$ \\
YES & $21(4.17 \%)$ & $116(23.02 \%)$ & $137(27.18 \%)$ \\
Total & $44(8.73 \%)$ & $124(24.6 \%)$ & $168(33.33 \%)$ \\
\hline \hline CIL & \multicolumn{2}{c}{ Rational expectations } \\
\hline Adaptive expectations & NO & YES & Total \\
NO & $58(11.51 \%)$ & $16(3.17 \%)$ & $74(14.68 \%)$ \\
YES & $64(12.7 \%)$ & $366(72.62 \%)$ & $430(85.32 \%)$ \\
Total & $122(24.21 \%)$ & $382(75.79 \%)$ & $504(100 \%)$ \\
\hline
\end{tabular}

\section{F. Analysis without outliers}

In this section, we test whether the results of the paper are driven by those cases where the difference in expected profits between the two candidates was very large. We do so by replicating the analysis of the paper with the exclusion of the extreme observations. Outliers are detected using the Carling's (2000) median rule. ${ }^{6}$ In particular, we drop the observations where the difference in expected profits between the the more trustworthy candidate and the more competent candidate was larger than 41 experimental points and smaller than -30 experimental points (see Figure F1). ${ }^{7}$

\footnotetext{
${ }^{6}$ According to the Median Rule, outliers are the observations above an upper cut-off point $c^{U}$ and below an lower cut-off point $c^{L}$. These points are calculated as:

$$
\begin{aligned}
& c^{U}=q_{2}+k_{2}\left(q_{3}-q_{1}\right) \\
& c^{L}=q_{2}-k_{2}\left(q_{3}-q_{1}\right)
\end{aligned}
$$

where $q_{1}, q_{2}$, and $q_{3}$ are the first, second, and third quartile respectively, while $k_{2}$ is a constant based on a prespecified outside rate, and it is usually equal to about 2 (Carling, 2000).

${ }^{7}$ Similar cut-off points are obtained if we use the Tuckey's Rule (Tuckey, 1977).
} 
Figure F1: Histogram of the difference in expected profits

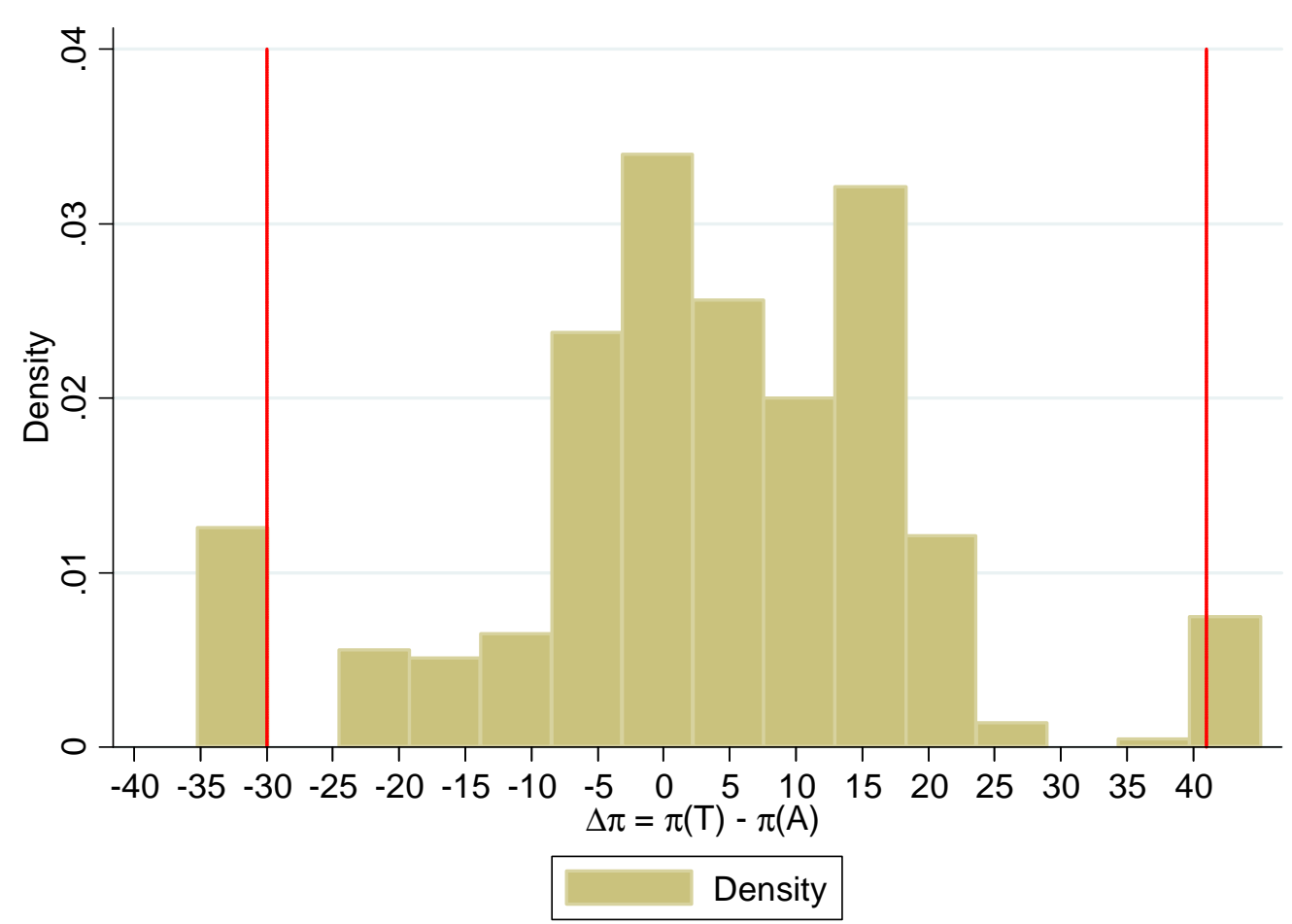

Notes: The data correspond to cases where there was a trade-off between comeptence and trustworthiness. The difference in expected profits is between the profit of the more trustworthy candidate and the profit of the more competent candidate. Outliers are located on the left and on the right of the first and second vertical line respectively.

Figure F2 shows the probability of electing the more trustworthy candidate as a function of the difference in expected payoffs between the more and less trustworthy candidate (as in Figure 2 of the paper). Even once we exclude the extreme cases, the area below the weighted running means for $\Delta \pi<0$ is bigger than the area above the weighted running means for $\Delta \pi>0$, particularly for small differences in expected payoffs $(|\Delta \pi| \leq 5)$. We also replicate the regression analysis of the paper (Table F1). With the removal of the outliers, the results do not change. If anything, the point estimates slightly increase both for trustworthiness and competence, and their difference acquires more significance. In particular, the coefficient of $\log$ (trustworthiness) is significantly larger than the coefficient of $\log ($ competence $)$ in Regression $2\left(\chi^{2}\right.$ test, $\left.p=0.079\right)$, Regression $3(p=0.030)$, Regression 5 $(p=0.044)$ and Regression $6(p=0.024)$. 
Figure F2: Probability of electing the more trustworthy candidate

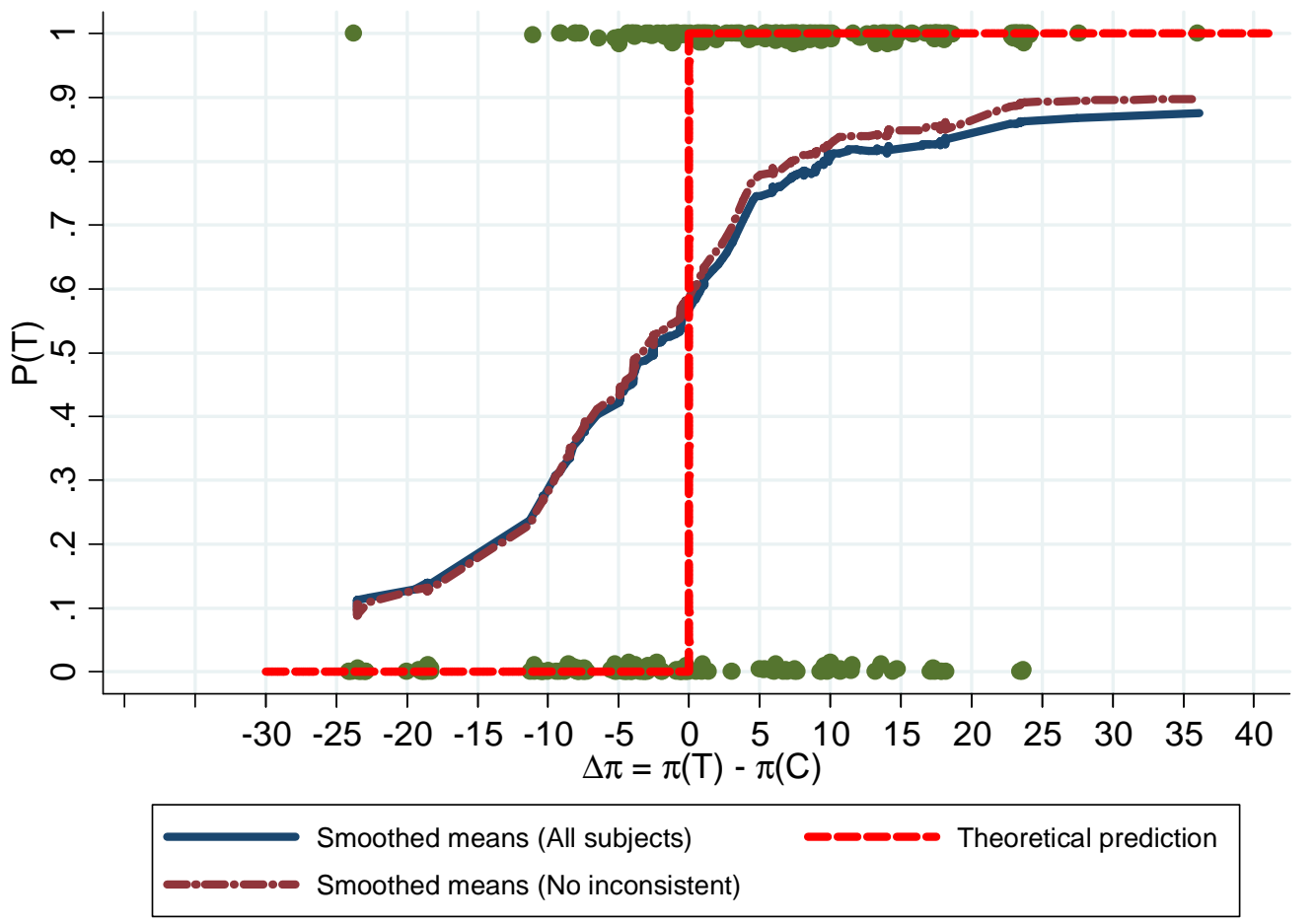

Notes: $\mathrm{P}(\mathrm{T})$ is the probability of electing the more trustowrthy candidate. $\Delta \pi$ is the difference in expected payoffs between the more and less trustworthy candidate. The running means are weighted to give more importance to near points than far, and computed using a bandwith of 0.6 (60\% of the data). 
Table F1: Alternative-specific conditional logit regressions

\begin{tabular}{|c|c|c|c|c|c|c|}
\hline & \multicolumn{2}{|c|}{ Regression 1} & \multicolumn{2}{|c|}{ Regression 2} & \multicolumn{2}{|c|}{ Regression 3} \\
\hline & $\mathrm{b}$ & $\mathrm{se}$ & $\mathrm{b}$ & se & $\mathrm{b}$ & se \\
\hline $\log$ (Trustworthiness) & $1.60^{* * * *}$ & 0.25 & $3.69 * * *$ & 1.11 & $4.27 * * *$ & 1.37 \\
\hline $\log ($ Competence $)$ & $1.56^{* * *}$ & 0.27 & $2.82 * * *$ & 0.82 & $2.27 *$ & 1.36 \\
\hline $\log ($ Trustworthiness $) \times|\pi|>5$ & & & $-2.13 * *$ & 1.03 & $-2.39 * *$ & 1.11 \\
\hline $\log ($ Competence $) \times|\pi|>5$ & & & -1.07 & 0.82 & $-1.54 *$ & 0.89 \\
\hline $\begin{array}{l}\text { Interactions with demographic, } \\
\text { behavioral, psychological and } \\
\text { treatment variables }\end{array}$ & \multicolumn{2}{|l|}{ No } & \multicolumn{2}{|c|}{ No } & \multicolumn{2}{|c|}{ Yes } \\
\hline Obs & 692 & & 692 & & 690 & \\
\hline Pseudo R2 & 0.24 & & 0.25 & & 0.30 & \\
\hline Df & 2 & & 4 & & 30 & \\
\hline \multirow[t]{3}{*}{ Prob $>$ F } & 0 & & 0 & & 0 & \\
\hline & \multicolumn{2}{|c|}{ Regression 4} & \multicolumn{2}{|c|}{ Regression 5} & \multicolumn{2}{|c|}{ Regression 6} \\
\hline & $\mathrm{b}$ & se & $\mathrm{b}$ & se & $\mathrm{b}$ & $\mathrm{se}$ \\
\hline $\log$ (Trustworthiness) & $1.81^{* * * *}$ & 0.3 & $3.94 * * *$ & 1.18 & $4.86 * * *$ & 1.63 \\
\hline $\log ($ Competence $)$ & $1.61 * * *$ & 0.3 & $2.86^{* * *}$ & 0.84 & $2.28^{*}$ & 1.34 \\
\hline $\log ($ Trustworthiness $) \times$ Inconsistency & $-1.38 * * *$ & 0.53 & $-1.25 * *$ & 0.51 & $-2.38 * * *$ & 0.66 \\
\hline $\log ($ Competence $) \times$ Inconsistency & 0.04 & 0.73 & 0.29 & 0.86 & -0.26 & 0.89 \\
\hline $\log ($ Trustworthiness $) \times|\pi|>5$ & & & $-2.20 * *$ & 1.11 & $-2.45^{*}$ & 1.26 \\
\hline $\log ($ Competence $) \times|\pi|>5$ & & & -1.1 & 0.85 & -1.53 & 0.93 \\
\hline $\begin{array}{l}\text { Interactions with demographic, } \\
\text { behavioral, psychological and } \\
\text { treatment variables }\end{array}$ & \multicolumn{2}{|l|}{ No } & \multicolumn{2}{|c|}{ No } & \multicolumn{2}{|c|}{ Yes } \\
\hline Obs & \multicolumn{2}{|l|}{692} & \multicolumn{2}{|l|}{692} & \multicolumn{2}{|l|}{690} \\
\hline Pseudo $\mathrm{R}^{2}$ & \multicolumn{2}{|l|}{0.27} & \multicolumn{2}{|l|}{0.28} & \multicolumn{2}{|l|}{0.35} \\
\hline Df & \multicolumn{2}{|l|}{4} & \multicolumn{2}{|l|}{6} & \multicolumn{2}{|l|}{32} \\
\hline Prob $>F$ & \multicolumn{2}{|l|}{0} & \multicolumn{2}{|l|}{0} & \multicolumn{2}{|l|}{0} \\
\hline
\end{tabular}

Notes: Alternative-specific logit regression with clustered robust standard errors. The table reports the beta coefficients and the standard errors. The demographic variables are age, gender $(=1$ for men), economics background (= 1 if applicable), nationality (UK $=1$ for UK subjects, and China $=1$ for Chinese subjects), and University status (= 1 for undergraduate students). The behavioral variables are the competence and trustworthiness of the voter. The psychological variables are the risk attitude, the SDS17 score and MACH score. The treatment variables are the CIL sessions, and the sessions where the trust game stage took place before the real effort task stage. The psychological and behavioral variables and age are centered at the mean in order to control for high correlation between the independent variables (see Marquardt, 1980). 'China' identifies subjects from China, Taiwan or Hong Kong. The data correspond to cases where there was a trade-off between trustworthiness and competence. The full regressions are available from the authors upon request. $* p<0.1, * *$ $p<0.05, * * * p<0.01$.

\section{References Not in Paper}

Carling, K. 2000. "Resistant Outlier Rules and the Non-Gaussian Case", Computational

Statistics and Data Analysis, 33 (3): 249-258.

Tukey, J.W. 1977. Exploratory Data Analysis. Reading, MA: Addison-Wesley. 


\section{G. Analysis of the public officials' behavior}

We now look at the behavior of subjects in the third stage of the expeirment (the Official's Dilemma Game). Table G1 reports the average competence in the $1^{\text {st }}$ and $2^{\text {nd }}$ realeffort task for each treatment. In the $2^{\text {nd }}$ real effort task, we do not detect any statistically significant differences in competence across treatments both in bivariate tests (MannWhitney test, $p>0.1$ ) and in aggregate (Kruskal-Wallis test, $p>0.1){ }^{8}$

Table G1: Competence in the $1^{\text {st }}$ and $2^{\text {nd }}$ real effort task

\begin{tabular}{|c|c|c|c|c|}
\hline \multicolumn{5}{|c|}{$1^{1^{\text {st }}}$ real effort task } \\
\hline & & Real effort Task first & Trust Game first & Total \\
\hline \multirow{2}{*}{\multicolumn{2}{|c|}{$\begin{array}{c}\text { Non-appointed }^{\mathrm{a}} \\
\text { Appointed }^{\mathrm{a}} \\
\end{array}$}} & $38.14(16.42)$ & $33.66(15.71)$ & $35.9(16.17)$ \\
\hline & & $42.2(20.09)$ & $38.98(18.95)$ & $40.59(19.47)$ \\
\hline \multicolumn{5}{|c|}{$2^{\text {nd }}$ real effort task } \\
\hline & & Real effort Task first & Trust Game first & Total \\
\hline \multirow{3}{*}{ Non-appointed } & Baseline & $41.27(21.61)$ & $40.13(17.68)$ & $40.7(19.66)$ \\
\hline & CIL & $38.42(20.86)$ & $39.42(19.75)$ & $38.92(20.11)$ \\
\hline & Total & $40.41(21.3)$ & $39.91(18.21)$ & $40.16(19.75)$ \\
\hline \multirow{3}{*}{ Appointed } & Baseline & $52.96(21.07)$ & $47.11(19.87)$ & $50.04(20.51)$ \\
\hline & CIL & $49.92(17.65)$ & $46.5(16.87)$ & $48.21(16.98)$ \\
\hline & Total & $52.05(19.93)$ & $46.93(18.81)$ & $49.49(19.43)$ \\
\hline
\end{tabular}

Notes: Standard deviations are in parenthesis. ${ }^{\text {a }}$ For the $1^{\text {st }}$ real effort task, we only report the total average of the Baseline and CIL treatments pooled together, since the two treatments were equivalent in the first two stages of the experiment (i.e. the treatment manipulation involved only stage 3 ).

If we compare the performance of subjects in the $1^{\text {st }}$ real-effort task (the one in stage 1 or 2) with the performance in the $2^{\text {nd }}$ real-effort task (the one in the Official's Dilemma Game), we observe, not surprisingly, that, because of learning, subjects performed better in the $2^{\text {nd }}$ real-effort task (Wilcoxon signed-rank test, $p<0.001$ ). This result is robust across treatments and for appointed and non-appointed participants respectively. Comparing the behavior of appointed and non-appointed participants, appointed participants performed better than non-appointed participants in the second real-effort task (Mann-Whitney test, $p=$ 0.004 ) but not in the first one ( $p=0.198$ ). This is not surprising since the performance of the non-appointed participants in stage 3 was not incentivized.

Appointed members had returned significantly more points in the earlier trust game than non-appointed participants $(p=0.001)$. This is unsurprising as trustworthy candidates were more likely to be appointed public official. Table G2 summarizes these statistics.

\footnotetext{
${ }^{8}$ Tests were performed for the entire sample, only for non-appointed participants, and only for appointed participants.
} 
Table G2: Trustworthiness in the $2^{\text {nd }}$ trust game

\begin{tabular}{lcccccc}
\hline & \multicolumn{3}{c}{ Non-appointed participants } & \multicolumn{3}{c}{ Appointed participants } \\
\hline Variable & n. & Mean & St. dev. & n. & Mean & St. dev. \\
\hline Return rate & 160 & 0.32 & 0.18 & 80 & 0.41 & 0.16 \\
\hline $\begin{array}{l}\text { Notes: 'Return rate' is equal to the amount returned by the trustee divided } \\
\text { by } 90 .\end{array}$
\end{tabular}

We can also study what explains the decision of the appointed participants to truthfully report the value of the common fund. Let the honesty rate be the proportion of the common fund reported by the public official to the other subjects. Table G3 shows average honesty rates for each experimental treatment. The honesty rate was significantly smaller in the sessions where the Trust Game was played first, both in aggregate (Mann-Whitney test, $p$ $=0.001)$ and separately for each treatment ( $p=0.026$ in the Baseline, and 0.011 in the CIL). A possible explanation of this finding is that, in those sessions, subjects required a higher return from the effort since the two real-effort tasks occurred one after the other, without any break or alternative task between them. In particular, subjects might have struggled more to complete the two tasks and believed to have exerted a higher effort. This potential explanation is supported by the fact that, looking at the data from the incetivized part of the final questionnaire, a higher proportion of subjects in the sessions where the trust game stage took place first felt they were ranked first among the three participants in terms of number of tables correctly solved in the first real effort task, compared to subjects who participated in the sessions where the real effort task stage took place first $\left(\chi^{2}\right.$ test, $\left.p=0.020\right){ }^{9}$

Table G3: Rate of honesty

\begin{tabular}{ccc}
\hline & $\begin{array}{c}\text { Real-Effort Task first } \\
(\mathbf{n}=\mathbf{4 2})\end{array}$ & $\begin{array}{c}\text { Trust Game first } \\
(\mathbf{n = 4 2})\end{array}$ \\
\hline Baseline $(\mathbf{n = 5 6})$ & $0.67(0.28)$ & $0.49(0.30)$ \\
CIL $(\mathbf{n}=\mathbf{2 4})$ & $0.70(0.18)$ & $0.47(0.21)$ \\
\hline
\end{tabular}

Notes: Average honesty rate. Standard deviation is in parenthesis.

We can regress the honesty rate against the socio-demographic, psychological and behavioral characteristics of the appointed co-participant, and the treatments dummies. ${ }^{10}$ Table G4 reports the results of this regression. Subjects who were more trustworthy in the trust game displayed a higher honesty rate. Subjects with higher scores in the

\footnotetext{
${ }^{9}$ Specifically, in the sessions where the trust game (real effort task) was played first, $60 \%$ (32.50\%) of the subjects felt they were rank first, $37.50 \%(52.50 \%)$ second and $2.50 \%(15 \%)$ third.

${ }^{10}$ Given the exploratory nature of this and later analysis, we only focus on $p<0.05$ (or better) significance levels in the text.
} 
Machiavellianism scale were more dishonest. Participants in the sessions where the trust game was played first were also generally more dishonest than other subjects.

Table G4: Tobit regression (Rate of honesty)

\begin{tabular}{lcc}
\hline & \multicolumn{2}{c}{ Rate of honesty } \\
\cline { 2 - 3 } & $\mathrm{b}$ & $\mathrm{se}$ \\
\hline Return rate & $0.463^{* *}$ & 0.199 \\
Male & $-0.117^{*}$ & 0.07 \\
China & -0.075 & 0.076 \\
Economics & -0.031 & 0.069 \\
UK & 0.005 & 0.101 \\
Trust Game first & $-0.159^{* *}$ & 0.063 \\
CIL & 0.011 & 0.07 \\
Undergraduate & 0.06 & 0.082 \\
Age & 0.005 & 0.006 \\
Risk choice & 0 & 0.021 \\
MACH Score & $-0.007^{* *}$ & 0.003 \\
SDS17 Score & -0.006 & 0.011 \\
Competence $\left(2^{\text {nd }}{ }^{\text {real-effort task })}\right.$ & -0.002 & 0.002 \\
Constant & $0.617^{* * *}$ & 0.167 \\
\hline Obs & 80 & \\
$\mathrm{R}^{2}$ & 0.506 & \\
Df & 13 & \\
Prob $>$ F & 0.003 &
\end{tabular}

Notes: Tobit regression. The table reports the beta coefficients and the standard errors. 4 observations are left-censored, and 6 are right-censored. The psychological variables (i.e. SDS17 Score, MACH Score) are centered at the mean in order to control for high correlation between the independent variables (see Marquardt, 1980). 'Return rate' is equal to the amount returned by the trustee divided by $90 . * \mathrm{p}<0.1, * * \mathrm{p}<0.05, * * * \mathrm{p}<0.01$.

We can also look at how the honesty rate correlates with the beliefs of the subjects that we elicited in the first part of the incentivized final questionnaire and how these beliefs correlated each other. ${ }^{11}$ Table G5 shows the Spearman rank correlation coefficients of these measures. The only two statistically significant correlations at conservative significance levels are a positive one between actual honesty rate and considering oneself more competent than the others; and a somewhat paradoxical one by which public officials who perceive themeselves as having been relatively more trustworthy in the earlier stage are less likely to be trustworthy in the official reporting game, perhaps as a result of feeling that they already

\footnotetext{
${ }^{11}$ We can only look at correlations as the answers to the questionnaire could have been affected by the decision to truthfully report or underreport the value of the common fund.
} 
gave their share of contribution to the others early on and/or that the others had not been trustworthy enough. ${ }^{12}$

Table G5: Spearman $\rho$ (beliefs and honesty rate)

\begin{tabular}{|c|c|c|c|c|}
\hline & Honesty rate & All vote & "Underreporting & Rank competence \\
\hline Rate of honesty & 1 & & & \\
\hline All vote ${ }^{a}$ & 0.04 & 1 & & \\
\hline Underreporting $^{\mathrm{b}}$ & -0.18 & -0.17 & 1 & \\
\hline Rank competence ${ }^{c}$ & $0.36 * * *$ & $-0.19 *$ & -0.11 & 1 \\
\hline Rank trustworthiness ${ }^{\mathrm{d}}$ & $-0.20 *$ & -0.15 & $0.34 * * *$ & $-0.20 *$ \\
\hline
\end{tabular}

Notes: "Do you think both the other two co-participants voted for you as the appointed co-participant?" YES $=1, \mathrm{NO}=0 ;{ }^{\mathrm{b}}$ "Do you think that the co-participant, selected at random, who voted for you thought that you were going to underreport the value of the common fund?" $\mathrm{YES}=1, \mathrm{NO}=0$; $^{\mathrm{c}}$ "How do you feel you were ranked among the three co-participants in terms of number of tables correctly solved in stage $1 / 2$ ?" $1,2,3 ;{ }^{\mathrm{d}}$ "How do you feel you were ranked among the three co-participants in terms of number of points returned to participant A in stage $1 / 2$ ?" $1,2,3 . * p<0.1, * * p<0.05, * * * p<0.01$.

\footnotetext{
${ }^{12}$ As noted in the main paper, there was actually a positive relationship between actual trustworthiness in the early stage and actual trustworthiness in the official dilemma stage (Spearman's $\rho=0.28, p=0.011$ ).
} 


\section{G. Additional analysis of behavior in stages 1 and 2}

Table H1 reports the results of an OLS regression where the dependent variable is the measured competence in the $1^{\text {st }}$ real-effort task stage, and the results of a Tobit regression where the dependent variable is the measure of trustworthiness, that is the return rate, in the $1^{\text {st }}$ trust game. Independent variables include the socio-demographic and psychological characteristics of the subjects, and the treatment dummies.

Table H1: Regressions on Competence ( $1^{\text {st }}$ real-effort task) and Trustworthiness

\begin{tabular}{lccccc}
\hline \hline & \multicolumn{2}{c}{ Competence $^{\mathrm{a}}$} & & \multicolumn{2}{c}{ Trustworthiness $^{\mathrm{b}}$} \\
\cline { 2 - 3 } & $\mathrm{b}$ & $\mathrm{s}$ & $\mathrm{b}$ & $\mathrm{se}$ \\
\hline Male & 2.766 & 2.376 & & $-0.102^{* * * *}$ & 0.031 \\
China & 1.85 & 2.651 & & 0.007 & 0.034 \\
Economics & 1.94 & 2.351 & & $-0.053^{*}$ & 0.029 \\
UK & 4.104 & 3.118 & & 0.034 & 0.041 \\
Trust Game first & $-4.074^{*}$ & 2.203 & -0.011 & 0.027 \\
Undergraduate & -0.19 & 2.63 & & $-0.070^{* *}$ & 0.035 \\
Age & -0.26 & 0.277 & 0.004 & 0.004 \\
Risk choice & 1.204 & 0.744 & $-0.020^{* *}$ & 0.009 \\
MACH Score & $-0.252^{* *}$ & 0.112 & -0.001 & 0.001 \\
SDS17 Score & $-0.741^{*}$ & 0.417 & & 0.005 & 0.005 \\
Experience with grid & 3.535 & 2.373 &. &. \\
Constant & $66.807^{* * *}$ & 15.914 & $0.395^{* * *}$ & 0.107 \\
\hline Obs & 240 & & 240 & \\
$\mathrm{R}^{2}$ & 0.090 & & $0.492^{\mathrm{c}}$ & \\
Df & 11 & & 10 & \\
Prob > F & 0.03 & & 0 & \\
\hline
\end{tabular}

Notes: ${ }^{\mathrm{a}}$ OLS regression with robust standard errors; ${ }^{\mathrm{b}}$ Tobit regression with 51 left-censored and 2 right-censored observations. ${ }^{c}$ This is the McFadden's pseudo $\mathrm{R}^{2}$. The table reports the beta coefficients and the standard errors. The psychological variables (i.e. SDS17 Score, MACH Score) and Age are centered at the mean. 'Experience with grid' is a dummy taking value 1 if a subject previously participated in a similar real-effort task. $* p<0.1, * * p<0.05, * * * p<0.01$.

We find that competence was smaller in the sessions where the trust game stage took place first, and for participants who scored high in the MACH questionnaire. We also find that male subjects, undergraduate students, and less risk averse subjects returned less in the trust game.

If we look at the proportion of subjects who trusted the counterpart (Table H2), we do not detect any statistically significant diffferences across the sessions where the real effort task was played first and those where the trust game stage took place first $\left(\chi^{2}\right.$ test, $\left.p>0.1\right)$. 
Table H2: Trust

\begin{tabular}{cccc}
\hline \hline & $\begin{array}{c}\text { Real effort task stage first } \\
(\mathbf{n}=\mathbf{1 2 0})\end{array}$ & $\begin{array}{c}\text { Trust game stage first } \\
(\mathbf{n = 1 2 0})\end{array}$ & Total \\
\hline Trust & $0.63(0.48)$ & $0.7(0.46)$ & $0.67(0.47)$ \\
\hline
\end{tabular}

Notes: Standard deviations are in parenthesis.

This is also confirmed in a logit regression where the dependent variable is a dichotomous variable which takes value 1 if a subject trusts the counterpart and 0 if does not trust, and where we control for the socio-demographic and psychological characteristics and treatment dummies (Table H3). Male participants were less likely to trust the counterpart, whereas UK participants were more likely to trust.

Table H3: Logit Regression on Trust

\begin{tabular}{ccc}
\hline \hline & \multicolumn{2}{c}{ Trust } \\
\cline { 2 - 3 } & $\mathrm{b}$ & $\mathrm{se}$ \\
\hline Male & $-0.790^{* *}$ & 0.318 \\
China & 0.423 & 0.373 \\
Economics & -0.362 & 0.31 \\
UK & $0.884^{* *}$ & 0.434 \\
Trust Game first & 0.419 & 0.302 \\
Undergraduate & -0.522 & 0.389 \\
Age & $0.088^{*}$ & 0.046 \\
Risk choice & -0.062 & 0.089 \\
MACH Score & $-0.026^{*}$ & 0.014 \\
SDS17 Score & 0.002 & 0.052 \\
Constant & -0.948 & 1.345 \\
\hline Obs & 240 & \\
Pseudo R & 0.095 & \\
Df & 10 & \\
Prob $>\mathrm{F}$ & 0.005 & \\
\hline
\end{tabular}

Notes: Logit regression with robust standard errors. The table reports the beta coefficients and the standard errors. The psychological variables (i.e. SDS17 Score, MACH Score) and Age are centered at the mean. $* p<0.1, * * p<0.05$, *** $p<$ 0.01 . 